\title{
3. Aussprache und Schlußworte
}

\section{Der Schutz der Allgemeinheit und der individuellen Rechte durch die polizei- und ordnungsrechtlichen Handlungsvollmachten der Exekutive}

Vorsitzender (Isensee): Ich darf Sie begrüßen zu Beginn unserer Aussprache über das verwaltungsrechtliche Thema.

Der erste Themenkreis „Schutzaufgaben und Schutzgüter der Polizei und Ordnungsverwaltung" sollte am Anfang stehen, an zweiter Stelle der Themenkreis „Handlungsbefugnisse und Handlungspflichten der Polizei und Ordnungsverwaltung" und an dritter "Adressaten und Mittel des polizei- und ordnungsbehördlichen Handelns" sowie - falls es sinnvoll erscheint ein vierter Themenkreis, der die Sonderprobleme der Differenzierung des Rechts der öffentlichen Sicherheit und Ordnung in einzelnen Disziplinen behandelt, soweit sie sich nicht in das große Koordinatensystem einfügen lassen.

Vorzuschalten sind unseren Uberlegungen zwei Länderberichte. Uber die Rechtslage in der Schweiz hat sich freundlicherweise Herr Kollege Eichenberger aus Basel bereit erklärt zu sprechen.

Eichenberger: Sehr geehrte Herren Kollegen! Das Polizeirecht als einheitliches Rechtsgebiet ist in der Schweiz dogmatisch relativ wenig bearbeitet. Die Gesetzgebung mutet rückständig an. Die Generalermächtigungen z. B. beruhen, außer beim Schutz des Staates und seiner Einrichtungen, großenteils auf Gewohnheitsrecht, partiell verfeinert durch differenzierendes Richterrecht.

Rechtspolitisch stößt jede Fortführung des geschriebenen Polizeirechts rasch auf das verbreitete Vorurteil, Polizei sei notwendig freiheitsfeindlich. Man huldigt gerne der Auffassung, Polizei sei exklusiv bewahrende und möglichst nur repressive Gefahrenabwehr. Man hofft, mit Hilfe begrifflicher Rigorositäten Freiheitsverluste einzudämmen, die befürchtet werden, wenn unter dem Titel der Polizei Wohlfahrtsförderung oder Sozialgestaltung statthätte. Trotzdem ist die Auflockerung oder Wandlung des Polizeibegriffs, wie die Berichterstatter heute 
für die Bundesrepublik dargelegt haben, auch in der Schweiz in vollem Gange und ungefähr auf dem gleichen Stande, wie er hier geschildert wurde.

Erheblich praktische Bedeutung wächst dem Polizeibegriff in der Schweiz aber immer noch deswegen zu, weil daran nicht nur Organkompetenzen, sondern auch Verbandskompetenzen geheftet sind. In etlichen Aufgabenbereichen, vorwiegend im Wirtschaftsrecht, wird die Kompetenzverteilung zwischen Bund und Kantonen so getroffen, daß zum Beispiel den Gliedstaaten bloß polizeirechtliche Befugnisse zugestanden sind.

Dem Polizeirecht wird auf weiten Ebenen eine Abgrenzungs- und Zumessungsfunktion zugedacht. Die Bemühungen um die Entpolizeilichung und um den Aufbau eines nominellen Ordnungsrechts neben dem Polizeirecht hat die Schweiz nicht mitmachen müssen. Doch steckt sie, wie angedeutet, in einer der Bundesrepublik ähnlichen Problematik. Ich will stichwortartig auf einiges hinweisen.

Offentliche Ordnung und Sicherheit als die Kernbegriffe des Polizeirechtes sind wahrscheinlich im Grunde genommen normative Zielbegriffe. Sie sind auf wechselnde Sachverhalte bezogen und verweisen notwendig auf externe Wertungen. Sie werden ihrerseits, wie es kürzlich gekennzeichnet wurde ( $A n$ dreas Jost), durch die Polizeigüter oder Schutzgüter erst konstituiert. Die öffentliche Ordnung und Sicherheit selbst sind also nicht eigentlich Schutzgüter, sondern eine in concreto immer wieder angestrebte Lage des Gemeinwesens.

Die üblichen Aufzählungen der Schutzgüterarten, wie etwa Leben, Gesundheit, Sittlichkeit, Ehre oder Vermögen, sind nicht abschließend, vielmehr auch dem Wandel unterworfen. Es kennzeichnet das pluralistisch-demokratische Staatswesen in seiner Offenheit für die Festlegung der Staatsaufgaben zweiter Stufe, daß nicht nur Inhalt und Umfang, sondern schon der Bestand gewisser Schutzgüter umstritten sein kann, zum Beispiel, ob das Geldwesen zur Bekämpfung des Geldwertzerfalls in einer Geldpolizei zu erfassen sei oder ob Qualitätskontrollen von Exportprodukten, zum Beispiel Pharmazeutika, Käse oder Uhren, zur Sicherstellung des Ansehens einer Gesamtwirtschaft polizeirechtlich begründet werden könnten.

Dennoch bleibt die Bestimmung der Schutzgüter zu einem gegebenen Zeitpunkt relevant, wenn man auf die Kategorie Polizeirecht überhaupt nicht verzichten will. Die dauernde Veränderung will ich an drei Beispielen kurz signalisieren.

Wohl am auffälligsten ist der Wandel bei der öffentlichen Sittlichkeit. In den meisten Kantonen ist die Filmzensur gefal- 
len, allerdings um den Preis der Kriminalisierung der Vorführung grobanstößiger Streifen. In religiösen Belangen scheinen Empfindlichkeiten abgebaut zu sein. Ob die industrielle Tierhaltung, zum Beispiel von Leghühnern, polizeilich eingedämmt oder verboten werden soll, bewegt zur Zeit die Gemüter. Hingegen können die Kantone immer noch das Konkubinat untersagen, und im Jugendschutz machen sich gelegentlich Strömungen zur Verstärkung bemerkbar. Zugleich bricht das Bedürfnis auf, Belästigungen, deren Abwehr herkömmlicherweise ja nicht zur Polizei gehört, einzubeziehen. Der Schutz der Intimsphäre und einer ungestört selbstbestimmten Lebensführung melden sich an, womit sich zugleich eine Drittwirkung der persönlichen Freiheit realisiert. Das Schutzgut der Gesundheit hat sich ausgeweitet über die Bekämpfung übertragbarer Krankheiten und Epidemien sowie den Lebensmittel- und Arzneimittelschutz hinaus.

Ladenschließungszeiten, Freizeit- und Ferienordnungen, vielfache Regelungen im Baupolizeirecht werden gesundheitspolizeilich begründet. Die Entwicklung des gesundheitspolizeilichen Bereichs ist ungezügelt, seit die Weltgesundheitsorganisation mit ihrer influenzierenden Wirkung „das vollständige körperliche, geistige und soziale Wohlergehen" in die Definition der Gesundheit eingebracht hat, denn es gibt nur noch wenige individuelle und kollektive Handlungen und Zustände, die nicht direkte Bezüge zu solchem vielschichtigen Wohlergehen aufwiesen. Offen ist zum Beispiel, ob dem Turnen und Sport, ob Altersfürsorgen, ja, ob dem Unterhalt von Wanderwegen als polizeilichen Vorkehren die Deutung zuzuweisen sei. Nicht ausdiskutiert und erst im Beginn begriffen ist, ob letztlich eigentlich der Umweltschutz mit Einschluß des ganzen Immissionenschutzes bei der weit verstandenen Gesundheitspolizei unterzubringen wäre.

Bei der Wirtschaftspolizei prallen wirtschaftspolitische Grundanschauungen, aber auch interessanterweise föderative Sorgen aufeinander, sobald es um den Inhalt und Umfang des Polizeibereichs geht. Daß Treu und Glauben im Geschäftsverkehr Schutzgut bildet, also der Vertrauensschutz und die Verhinderung der Publikumsausbeutung bei Maßangaben, Datenvermerken, Preisanschriften, Beschaffenheitshinweisen, ist zwar erhärtet, trotzdem ist große Unruhe im Felde. So steht etwa die Frage an, ob ein garantierter Mindestlohn zur Sicherung des Existenzminimums polizeilich zu begründen wäre. Korrektes Geschäftsgebaren im Bankenwesen, im Versicherungswesen und bei Anlagefonds kann polizeilich sichergestellt werden. Nun aber wird Publikumsschutz auch geltend gemacht bei der For- 
derung, die Geschäftsführung von Großunternehmen offenzulegen. Schließlich etabliert sich die Meinung, über die Sicherung des lauteren Wettbewerbs hinaus, über die Kriegsvorsorgen und die Energieversorgungen hinaus sei in Erwägung zu ziehen, sogar Kerngebiete der wirtschaftlichen Stabilität als Polizeigut zu behandeln.

Der gleichsam flüssige Zustand der Schutzgüter und die unabsehbaren Weitungsmöglichkeiten der Gefahrenquellen lösen eine ambivalente Haltung aus. Einerseits drängen sie jetzt erst recht auf eine offene Fassung des Polizeibegriffs, auf die Bekräftigung von Generalermächtigungen und auf die Hervorstreichung des Opportunitätsprinzips. Man erwartet daraus die der heutigen Gesellschaft angemessene Reaktionsfähigkeit des Gemeinwesens, um die Gefahren tatsächlich zu meistern.

Andererseits sieht man angesichts der erwähnten Ausweitung und wachsenden Unbestimmtheit der Schutzgüter eine Ausuferung des Staates, die tberdimensionierung des Ermessens, das Entgleiten der Subsidiarität und die Bedrängung des Legalitätsprinzips, dann aber auch das enorme Risiko, daß die Behörden wirkliche Gefahren nicht erkennen und die gebotenen Handlungen unterlassen könnten.

Hier wirkt man nun auf Spezialermächtigung mit generellabstrakten Aufgabenzuweisungen hin, wie es heute morgen dargelegt wurde. Damit aber akzeptiert man in weitem Maße abstrakte Gefahrenabwehr und fast grenzenlos präventive Maßnahmen.

Der Entscheid für oder wider Spezialgesetzgebungen stößt freilich auf ein legislatorisches Paradox. Effektive und steuernde Spezialgesetzgebungen setzen in der Regel ein gesichertes Erfahrungsgut und bewährte Grundsätze voraus, und die kann man bei neuartigen Gefahrensachverhalten ja nicht haben. Dafür wären Generalermächtigungen technisch zweckmäBiger. Doch diese gerade bei hochgradigen Gefahren sind wiederum rechtsstaatlich und demokratisch bedenklich. Es passiert Spezialgesetzen in der Schweiz, daß sie die realen Gefahren, die adäquaten Maßnahmen, die freiheitsschützenden Begleitvorkehren und die den Demokratie- und Rechtsstaatsbedürfnissen entsprechenden Kompetenzordnungen nicht angehen oder nicht treffen. Sie bleiben dann vorwiegend Beruhigungsakt für die Bevölkerung und die Behörden. So hat der Gesetzgeber im Gewässerschutz, bei der Atomenergie und versuchsweise beim Umweltschutz partienweise ins Leere gegriffen.

Man versucht jetzt mitunter, wie Herr Kollege Knemeyer dargelegt hat, auch in der Schweiz, durch Zwecknormen die 
Verwaltung zum Handeln und zur bereichsspezifischen Mittelverwendung zu veranlassen. Doch wer die Schwierigkeiten des schweizerischen Gesetzgebers kennt, tragfeste und steuerungsfähige Zwecknormen zu redigieren, wird die Rechtslage als kritisch beurteilen.

Das Opportunitätsprinzip mit dem Entschließungsermessen wird begrifflich jetzt zwar ausgeschaltet, dringt aber materiell durch die Hintertüre der unbestimmten Gesetzesbegriffe in der Zweckbestimmung annähernd wieder in die behördliche Werkstatt zurück, zumal da die Verbreiterung des richterlichen Kognitionsspektrums vom Ermessen zu unbestimmten Gesetzesbegriffen in neuen und komplexen Sachbereichen nicht erheblich sein kann, wenn man die Realität der Rechtsprechung betrachtet. $\mathrm{Zu}$ helfen wäre mit der festen Verankerung des Verhältnismäßigkeitsprinzips, aber man kann nicht behaupten, daß das nun im Inhalt und in der Steuerungsgewißheit schon auf dem Tische läge. Man hat es noch nicht in der Hand, obwohl es fleißig im Munde ist. Man könnte mit einer Verfestigung des Verhältnismäßigkeitsprinzips den Schreck dem Ermessen wahrscheinlich doch nehmen.

Die Spezialgesetzgebung wird nun trotz allem in der Schweiz kräftig vorangetrieben. Bei ihr liegt die Chance der Verbesserung des Polizeirechts. Zugleich aber ist der föderative Verlust eklatant. Die polizeiliche Spezialgesetzgebung drängt angesichts der Gefahrenquellen das Bundesrecht rapid zurück.

Ich darf noch kurz auf den Schutz des einzelnen hinweisen. Die Schweiz sucht ähnlich wie die Bundesrepublik sich durch die öffentliche und private Interessenlage durchzuschlagen. Es brauchte allerdings lange, bis Hans Huber das Bundesgericht dazu gebracht hatte, im Polizeirecht den Dritten als beschwerdeberechtigt anzuerkennen.

Neu bahnt sich an eine Ausweitung zu einer Konkurrenzbeschwerde in Wirtschaftssachen. Man kapriziert sich aber offensichtlich nicht länger darauf, öffentliche und private Interessen begrifflich präzis zu scheiden, und man kennt die schiere Unmöglichkeit, auszumachen, ob ein Rechtssatz ausschließlich der Allgemeinheit oder überdies dem einzelnen dienlich sein soll. Vielmehr behilft man sich in praxi mehr als in der Doktrin mit einer Wertung der Gefahr und der Schutzmöglichkeiten unter dem Gesichtspunkt der Zumutbarkeit. Man fragt: Ist in Anbetracht der gegebenen Sachlage dem Privaten zuzumuten, sich mit privatrechtlichen Mitteln zur Wehr zu setzen oder muß ihm vernünftigerweise polizeirechtlicher Schutz zukommen? 
Im Gebiete der Immissionen ist der polizeiliche Aktivitätskreis weit gediehen, nicht zuletzt bloß wegen der Schwerfälligkeit des zivilprozessualen Rechtsschutzes. Beim Schutz der Ehre oder der wirtschaftlichen Güter hingegen ist der Bereich für den einzelnen noch eng geblieben.

Bei Rauschgiftsüchtigen und Alkoholkranken, aber selbst beim Selbstmörder, wird die Selbstgefährdung für polizeiliche Maßnahmen als hinreichend behandelt, wie überhaupt bei den Wertungsvorgängen jetzt mehr noch als in den Behörden in der öffentlichen Meinung die Bereitschaft offenbar wächst, den Unvernünftigen in allen möglichen Lagen vor sich selbst $\mathrm{zu}$ schützen, so, als ob die Selbstbestimmung und, wenn wir es so nennen dürfen, die Freiheit zur folgenreichen Unmäßigkeit nur dem Vernünftigen zugestanden werden wollte.

Wagen wir für die Schweiz eine Gesamtbeurteilung, dann darf man festhalten, daß die Gesetzgebung für Generalermächtigungen der Zeit nachhinkt. Die Spezialgesetzgebung wird forciert, jetzt vorwiegend auf Bundesebene.

Wo aber die Kantone auftreten sollten, herrscht ein Zögern vor. Immerhin hilft das Bundesgericht nach, indem es die polizeiliche Generalklausel auch als ungeschriebenes Recht anerkennt, so daß alle Kantone sich auf sie berufen können. Man wird schwerlich einer akuten Gefahr mangels rechtssatzmäßiger Kompetenz nicht entgegentreten können, aber für Dauerlösungen und komplexe Sachverhalte sind die Basierungen oft zu schmal und zu brüchig.

Funk: Sehr verehrte Herren Kollegen! Wenn man die Situation des Polizeirechts und der Polizeirechtslehre in der Bundesrepublik mit jener in Österreich vergleicht, so zeigen sich erhebliche Unterschiede in den rechtlichen Grundlagen, in der wissenschaftsgeschichtlichen Entwicklung und in der Terminologie.

Für den österreichischen Bereich ist davon auszugehen, daß die Bemühungen der Polizeirechtswissenschaft des zu Ende gehenden 19. und des beginnenden 20. Jahrhunderts um die Gewinnung der theoretischen Grundlagen für eine rechtsstaatliche moderne Polizeiverwaltung von seiten der Wiener Schule des Rechtspositivismus fortgesetzt und in der Weise vorläufig zum Abschluß gebracht worden sind, daß der Polizeibegriff als rechtspolitisch überflüssig und rechtslogisch nicht haltbar angesehen wurde.

Das ist daraus zu erklären, daß die Denkstrategie dieser Richtung auf eine möglichst hohe Strenge im Analytischen und auf 
eine dementsprechend weitgehende Reduktion von rechtlichen Phänomenen auf deren strukturale Eigenschaften hin ausgerichtet war.

Das bedeutet naturgemäß einen Abbau von teleologisch bedingten Begriffen und Denkstandards, also auch des materiellen Polizeibegriffs, der ja dieser Kategorie von Begriffen zugehört.

Adolf Merkl hat die Entbehrlichkeit des Polizeibegriffs in eindrucksvoller Weise betont. Dieser Begriff habe auf rechtswissenschaftlicher Ebene keine Daseinsberechtigung, da er nicht geeignet sei, irgendeine positivrechtliche Besonderheit dessen anzuzeigen, was er bezeichnen will. Polizei sei in Wahrheit keine von der übrigen Verwaltung abgehobene Funktion, sondern ein rechtspolitisch-ideologischer Restbegriff.

Diese Einstellung der Verwaltungsrechtslehre gegenüber dem Polizeibegriff war in praktischer Hinsicht mit uneinheitlichen Implikationen und Auswirkungen verbunden. Einerseits waren damit jedem Autonomieanspruch der gefahrenabwehrenden Verwaltung, vor allem aber einer möglichen Flucht aus der Legalitätsbindung die theoretischen Grundlagen entzogen. Es war klargestellt, daß Polizeiverwaltung den gleichen Rechtsstaatlichkeitserfordernissen unterworfen ist wie die übrige Verwaltung auch. Allerdings zeigte die Fundamentalkritik der Wiener Schule am Polizeibegriff auch noch eine andere, der vollen rechtsstaatlichen Einbindung des Polizeilichen in Osterreich zumindest partiell entgegenwirkende Konsequenz. Der Umstand, daß der Polizeibegriff sozusagen zu einem Unbegriff geworden ist, dürfte doch erheblich zu der heute in Osterreich feststellbaren Unterentwicklung der Polizeirechtslehre und der Polizeigesetzgebung beigetragen haben.

Die aktuelle Situation auf diesem Gebiet ist in ihren Umrissen durch folgende Faktoren charakterisierbar: Das Grundverständnis der Rechtsordnung und der Wissenschaft gegenüber der gefahrenabwehrenden Funktion der Verwaltung, also gegenüber dem materiellen Polizeibegriff, läßt nur Fragmente eines selbständigen materiellen Polizeibegriffs erkennen. Das Problem der Gefahrenabwehr als solches ist aber natürlich nach wie vor präsent. Somit ergibt sich in gewisser Hinsicht ein Nachholbedarf in der Problembewältigung auf seiten der Rechtsordnung und der Lehre gegenüber dem Polizeilichen. Lassen Sie mich das etwas näher ausführen.

Ein materieller Polizeibegriff ist in der österreichischen Rechtsordnung im wesentlichen in zwei dogmatisch bedeutsamen Ansätzen begründbar. Zum einen in der Vorstellung der 
Abwehr jener Gefahren, die für einzelne Verwaltungsgebiete bereichstypisch sind. Das wären also die speziellen "sicherheitsrechtlichen Bereiche" in der Terminologie der Bundesrepublik. In Osterreich spricht man hier von der sogenannten Verwaltungspolizei.

Demgegenüber steht nun der Bereich der allgemeinen und der örtlichen Sicherheitspolizei. Ich muß vorausschicken, daß es hier sowohl im Terminologischen wie auch im Substantiellen eine Fülle von ungelösten Schwierigkeiten und Unklarheiten gibt, die auszubreiten ich mir versagen muß.

In globaler Betrachtungsweise kann aber festgestellt werden, daß die Verwaltungspolizei zum Unterschied von der Sicherheitspolizei heute einen durchaus hohen und sachgerecht differenzierten Regelungsstandard erreicht hat, einen Standard, der dem Gebot des verfassungsrechtlichen Legalitätsprinzips durchaus entsprechend ist.

Anders dagegen sieht es auf dem Gebiet der Sicherheitspolizei aus. Hier muß zwischen der dem Bund vorbehaltenen sogenannten allgemeinen Sicherheitspolizei und der den Gemeinden zur Vollziehung im eigenen Wirkungsbereich überwiesenen sogenannten örtlichen Sicherheitspolizei unterschieden werden. Für beide Bereiche gibt es Handlungsermächtigungen in Form von klassischen, auf Verfassungsgesetzesstufe stehenden Generalklauseln sowie auf einfachgesetzlicher Ebene in Form von verstreuten Grundlagen für die wichtigsten polizeilichen Standardmaßnahmen, wie Verhaftung, Hausdurchsuchung, Beschlagnahme, Waffengebrauch und ähnliches.

Von besonderem Interesse ist die Generalklausel für die Führung der allgemeinen Sicherheitspolizei des Bundes. Sie findet sich in einem Verfassungsübergangsgesetz aus 1929 und enthält die allgemeine Ermächtigung für die mit der Führung der allgemeinen Sicherheitspolizei betrauten Behörden, die zum Schutz der gefährdeten körperlichen Sicherheit von Menschen oder des Eigentums innerhalb ihres Wirkungsbereiches zur Abwendung der Gefahr erforderlichen Anordnungen zu treffen und deren Nichtbefolgung zu Verwaltungsübertretungen zu erklären. Diese Anordnungen - das ist sehr wesentlich - dürfen allerdings nicht entgegen bestehenden gesetzlichen Vorschriften getroffen werden.

Diese Generalklausel stellt ein im Jahre 1929 geschaffenes Provisorium dar, das bis zur Erlassung eines Polizeibefugnisgesetzes des Bundes gelten sollte. Dieses Gesetz ist allerdings über das Stadium einer derzeit nicht aktuellen Regierungsvor- 
lage nicht hinausgekommen und dürfte auch für die nächste Zukunft kaum zu erwarten sein.

Die Folgen dieser Situation sind ein Gesetzgebungsdefizit auf dem Gebiete der allgemeinen Sicherheitspolizei sowie das Fehlen einer systematischen Polizeirechtsdogmatik und eine Reihe von praktischen Rechtsschutzproblemen.

Bezüglich letzterer hat zwar der Verfassungsgerichtshof durch eine rechtsschutzfreundliche Judikatur Abhilfe geschaffen. Seit einer BVG-Novelle aus 1974 hat auch der Verwaltungsgerichtshof die Zuständigkeit zur Prüfung von nicht bescheidförmlichen polizeilichen Verwaltungsakten eingeräumt bekommen.

All dies bringt zwar eine gewisse Entlastung, kann aber den lückenhaften Zustand der rechtlichen Grundlagen, vor allem die Lücken in materieller Hinsicht nicht ausgleichen.

Bei diesem Stand oder - besser gesagt - dem fehlenden Stand an Gesetzgebung des Bundes ist es nicht verwunderlich, daß Tendenzen bei den Ländern sichtbar werden, in diesen Leerraum hineinzustoßen und das Vakuum zumindest zu einem Teil durch landesgesetzliche Regelungen aufzufüllen.

Von Verfassungsrechts wegen ist ein solches Geschehen zwar ausgeschlossen, da die Länder nach dem österreichischen Kompetenzverteilungssystem $\mathrm{zu}$ konkurrierender Gesetzgebung grundsätzlich nicht befugt sind. Da aber die Grenzen nicht streng operationalisierbar sind und zumeist nicht anders als teleologisch gezogen werden können, könnte es in Zukunft de facto zu einer Expansion der Landesgesetzgebung unter dem Titel der örtlichen Sicherheitspolizei mit einer bedenklichen Nähe zur Sicherheitspolizei des Bundes kommen. Ein jüngst ergangenes Vorarlberger Sicherheitsgesetz gibt Anlaß zu dieser Vermutung.

Soviel zum Materiellen.

Was den organisatorischen Polizeibegriff angeht, so ist hier eine ähnlich zerklüftete Rechtssituation festzustellen. Es gibt wohl Ansätze einer eigenen, spezialisierten Polizeibehördenorganisation. Es fehlt aber an ausreichend dichten gesetzesförmlichen Organisationsgrundlagen. Wir finden auch hier ein verfassungsgesetzlich legitimiertes, bis zur Schaffung eines Polizeiorganisationsgesetzes eingerichtetes Provisorium vor.

Das Polizeiorganisationsgesetz ist ebenso wie das Polizeibefugnisgesetz des Bundes weder ergangen noch für die nächste Zukunft zu erwarten. 
Sehr zum Unterschied vom Fehlen eines Polizeibefugnisgesetzes macht sich der defizitäre Zustand im Organisationsrecht für den einzelnen allerdings kaum in nachteiliger Weise bemerkbar. Hier geht es ja eher um verwaltungsorganisationspolitische Probleme, deren Lösung höchstens im inneren Bereich auf größere Schwierigkeiten stößt. Ich erwähne die Frage der Doppelgleisigkeit der Polizeiexekutive in Form eines $\mathrm{Ne}-$ beneinander von Bundespolizei und Bundesgendarmerie als zwei Parallelwachkorps.

Ich glaube, daß man bei der Beurteilung der zukünftigen Möglichkeiten und der Entwicklung des österreichischen Polizeirechts von zweierlei Erwartungen wird ausgehen müssen.

Einerseits wird der Gesetzgeber zu agieren haben, um den lückenhaften Zustand im Bereich des Polizeiorganisationsrechts, vor allem aber auf dem Sektor der allgemeinen sicherheitspolizeilichen Befugnisse $\mathrm{zu}$ beenden. Hier gilt es, den Handlungsauftrag der Polizei klar zu fassen und ebenso klare Regelungen über den Rechtsanspruch des einzelnen auf polizeiliches Handeln oder Unterlassen zu formulieren.

Bei der Ausgestaltung des Rechtsschutzes müßte auch einiges geschehen. Es wäre günstiger, wenn hier das System der vorgelagerten Administrativbeschwerde anstelle des jetzt geltenden Systems der Direktbeschwerde bei den Höchstgerichten gewählt würde.

Eine ebenso wichtige Ergänzung müßte darin liegen, daß das wissenschaftsgeschichtlich zu erklärende, der tatsächlichen Problemlage aber nicht adäquate Ruhen der Polizeirechtslehre überwunden wird. Die Wissenschaft hat in diesem Punkt eine wichtige Hilfs- und Korrektivfunktion für den Gesetzgeber zu erfüllen, kann aber - das möchte ich angesichts des bei uns dominierenden Legalitäts- und Wissenschaftsverständnisses betonen - das Tätigwerden des Gesetzgebers nicht ersetzen.

Vorsitzender: Wir kommen nun zum ersten Punkt der Diskussion: „Schutzaufgaben und Schutzgüter der Polizei und Ordnungsverwaltung."

Vogel: Beide Herren Referenten haben das Thema sehr grundsätzlich angefaßt. Sie haben, meine ich, recht daran getan, und wir sollten ihnen dankbar dafür sein. Denn von Begriffen und ihren Abgrenzungen haben wir in der gestrigen Diskussion schon sehr viel gehört; über Freiheit, Autonomie, deren Unterschiede, und so fort. Herr Erichsen hat zwar auch einige neue Begriffe eingeführt: „systemakzessorisch", "sy- 
stemstabilisierend" usw. Aber ich verstehe ihn doch wohl richtig dahin, daß er damit nichts grundsätzlich Neues ausdrücken wollte, sondern nur zeigen, daß das Polizeirecht auch mit diesen "schicken“ neuen Begriffen arbeiten kann, daß es nicht verstaubt ist - und das ist es ja auch nicht. Die Praxis wird allerdings wohl einige Zeit brauchen, bis sie sich an die neue Terminologie gewöhnt hat.

Die „klassische" Umschreibung der polizeilichen Aufgabe, d. h. ihre Umschreibung im Sinne des liberalen Rechtsstaates, ist, wie Sie wissen, entstanden als ein Versuch, die staatlichen Minimalzwecke zu bestimmen: diejenigen Zwecke, denen sich selbst der freiheitlichste Staat - etwa im Sinne der Forderungen des jungen von Humboldt - nicht entziehen kann. Da ist es natürlich interessant, daß jetzt Herr Erichsen wieder Wohlfahrtszwecke in den Polizeibegriff einbeziehen will — "wieder“ muß man sagen, denn sie waren ja schon einmal, vor dem liberalen Rechtsstaat, einbezogen gewesen. Diese Erweiterung scheint einleuchtend, wenn wir bedenken, daß wir heute die Staatszwecke erheblich weiter ziehen als der junge Humboldt; in der Sozialstaatsklausel kommt das zum Ausdruck. Aber ich würde doch dazu neigen, hier sehr behutsam $\mathrm{zu}$ verfahren: Ist es nicht ausreichend, wenn die Polizei - nur um sie geht es hier - soziale Zwecke dort fördert, wo solche Förderung Mittel der Gefahrenabwehr ist? Würde nicht schon das der Zielsetzung von Herrn Erichsen genügen? Das entspräche einer Berücksichtigung der Wohlfahrtszwecke im Sinne der Ihnen bekannten Formel Pütters: „ut tanto lautior sit status isti malo, quod metuebatur, directe oppositus“. Das freilich ist stets als polizeiliche Aufgabe anerkannt worden (und es schließt den Verkehrskasper ein).

Noch kurz ein Wort zur öffentlichen Ordnung. Der differenzierenden Bewertung durch Herrn Erichsen kann ich, glaube ich, zustimmen. Ein verfassungskonform ausgelegter Begriff der öffentlichen Ordnung schränkt, meine ich, die Freiheit nicht ein; im Gegenteil ist er geeignet, sich einem größeren Freiheitsbedürfnis der Gesellschaft flexibel anzupassen. Ohne den Begriff der öffentlichen Ordnung wäre seinerzeit der ZwickelErlaß vermutlich durch Gesetz eingeführt worden und - wie etwa hier in Baden die Strafbarkeit des Konkubinats - erst im vergangenen Jahr wieder aufgehoben worden.

Allerdings zeigt sich dabei auch gleich, daß die Einbeziehung sozialer Ziele in den Polizeibegriff ihren Pferdefuß hat. Herr Erichsen, würden Sie meinen, daß gesellschaftliche Vorstellungen (ich sage "gesellschaftliche Vorstellungen“, denn wenn es 
sich um Regelkreise handelte, brauchte nicht der Staat schützend einzugreifen) über wünschenswerte Wohlfahrtspflege jetzt ebenfalls als öffentliche Ordnung geschützt werden sollen? Das würde mir doch zu weit gehen.

Häberle: Ich möchte zu Ihrem ersten Gliederungspunkt, Herr Vorsitzender, Stellung nehmen, und zwar auf dem Hintergrund von Herrn Erichsens Leitsätzen 4, 35 bzw. 33 und 4, 12, 18, grundsätzlich zustimmend, nur zum Teil kritisch. Es geht mir um die Strukturierung und inhaltliche Bestimmung der Probleme des staatlichen Polizeiauftrages bzw. der Schutzgüter „öffentliche Sicherheit und Ordnung" im politischen Gemeinwesen. Dies soll unter drei Aspekten geschehen. Erstens: Welches ist der Ort des staatlichen Polizeiauftrags im verfassungsrechtlichen Koordinatensystem? Zweitens: Welches ist die rechtstheoretische Struktur des Begriffs „öffentliche Sicherheit und Ordnung"? Drittens folgt eine Bemerkung zur Ambivalenz im Verhältnis zwischen Grundrechten und Polizei bzw. öffentlicher Sicherheit und Ordnung.

Im einzelnen: Herr Erichsen hat in Leitsatz 4 mit vollem Fecht auf die Verfassungsbedingtheit des staatlichen Polizeiauftrags und der „öffentlichen Sicherheit und Ordnung“ hingewiesen. Weitergehend und positiver möchte ich formulieren, daß der polizeiliche Schutzauftrag "verfassungserfüllender" Natur und „verfassungserfüllt" ist. Konkret bedeutet das im Blick auf die Grundrechte, daß sich unser "Grundrechtsstaat" und unsere "Grundrechtsgesellschaft" mit ihren spezifischen Staatszielen verfassungsunmittelbar auf die inhaltliche Bestimmung dessen auswirken, was der staatliche Polizeiauftrag ist und was er im Wandel des Staatsverständnisses sein kann. Eben deshalb, Herr Erichsen, vermisse ich doch einen Aspekt: die Frage, wie die Probleme der pluralistischen Demokratie auf den staatlichen polizeilichen Schutzauftrag, die Begriffe „öffentliche Sicherheit und öffentliche Ordnung" und das Recht der Polizei einwirken.

Zweitens, ein Wort zur Struktur des Begriffs „öffentliche Sicherheit und Ordnung": Ich meine, es handelt sich dabei um einen typischen Relationsbegriff, einen Begriff also, der auf die verschiedenen verfassungsrechtlichen Güter Bezug nimmt und sie jeweils konkretisierend aufnimmt, darüber hinaus um einen Begriff, der sehr stark öffentlichkeitsbezogen ist. Das klingt in Herrn Erichsens Leitsatz 33 zur "Veröffentlichung" an. "Öffentliche Sicherheit und Ordnung" verweisen auf die pluralistische Offentlichkeit, in all ihren feinen Differenzie- 
rungen, und die "gesellschaftlichen Anschauungen" sehe ich, stärker als Herr Vogel soeben, mehr in ihrem Wandel, das bestätigt auch die Praxis. Es sind mannigfache Offentlichkeitskristallisationen, die so, bei aller gebotenen Vorsicht, in die Begriffe der öffentlichen Sicherheit und Ordnung hineinwirken. Also: Wandlungsoffenheit als Stichwort.

Der dritte Punkt-er ist wohl angedeutet in Herrn Erichsens Leitsatz 4 in Verbindung mit Leitsatz 12 - lautet als These: Zwischen den grundrechtlichen Freiheiten und dem staatlichen Polizeiauftrag zum Schutz von öffentlicher Sicherheit und Ordnung besteht ein ambivalentes Verhältnis. Einerseits begrenzt der staatliche, verfassungsrechtlich begründete Polizeiauftrag die Grundrechte, das ist augenfällig; andererseits sind aber diese Grundfreiheiten als private und öffentliche Freiheiten wesentlich konstituierende Bestandteile dieser öffentlichen Sicherheit und Ordnung durch die Polizei: Grundrechte als polizeiliche Gemeinwohlgüter. Das läßt sich meines Erachtens als Verhältnis der "Ambivalenz" in der heutigen Polizei unseres freiheitlichen Gemeinwesens kennzeichnen, wobei es dann zu den im Erstbericht herausgestellten Abwägungen kommt.

Erlauben Sie eine Schlußfrage an Herrn Knemeyer: Welches ist das Verhältnis von Opportunitätsprinzip und Ermessen in Ihrer Sicht? Sind Sie in der Normativierung des Ermessensspielraums (Leitsatz 14, 22) nicht zu weit gegangen?

Quaritsch: Eine Frage an Herrn Erichsen zu seinen Ausführungen betr. Leitsätze 27 und 28. Für die Erheblichkeit der Interessen in einem "mehrdimensionalen Rechtsgut- und $\mathrm{Ab}$ wägungsgefüge" wurde dargelegt, es könne zu einer Kollision von Steuerinteressen und polizeilichen Interessen kommen. Sie haben vorgetragen, Herr Erichsen, nach der Rechtsprechung könne die öffentliche Sicherheit gegenüber diesen fiskalischen Interessen zurücktreten. Ich kann mir im Moment keinen praktischen Fall vorstellen, in dem diese Aussage relevant sein würde. Meine Bitte: Können Sie Ihre Feststellung anhand eines praktischen Falles erläutern?

Erichsen: Herr Quaritsch, ich bitte um Nachsicht, wenn ich mich mißverständlich ausgedrückt haben sollte. Ich habe im Abschnitt VIII der Leitsätze eine Frage aufwerfen wollen, um deutlich zu machen, daß wir hier an gewisse, bisher sehr stabilisierte Grenzen unseres Denkens stoßen. Unter den Fällen, die ich im Auge hatte, sind gerade keine, in denen es die Rechtsprechung für möglich gehalten hat, daß fiskalische, also etwa 
Steuerinteressen, gegenüber Sicherheitsinteressen durchgreifen. Ich persönlich würde das auch nicht für richtig halten.

Hans Peter Ipsen: Ich habe nur eine Frage im Zusammenhang mit der These 2 von Herrn Erichsen. Die Aufbereitung des Rechts der allgemeinen Gefahrenabwehr könne, so heißt es dort, die Rückbindung der zur Isolierung tendierenden sondergesetzlichen Ordnungen ermöglichen. Meine Frage geht dahin, ob diese Erwartung und Chance von Herrn Erichsen auch für Bereiche der Wirtschaftsaufsicht gesehen wird, die zum Teil ja aus der Gefahrenabwehr der Gewerbepolizei entwickelt worden ist. Ich denke etwa an die Versicherungsaufsicht, an die Kartellaufsicht, wo auch von Gefahren für Individuen gesprochen wird, die dort als Versicherungsnehmer oder Verbraucher gesehen werden. Das berührt Fragestellungen, die Herr Eichenberger für die Schweiz aufgeworfen hat. Es geht mir darum, ob die allgemeinen Erkenntnisse Ihrer Thesen 31 und 33 auch in diese Bereiche der Wirtschaftsaufsicht hinein erstreckbar sind und auch dort nutzbar sein könnten. Das zu hören, wäre angesichts der Isolierung jener Rechtsgebiete, deren Kommentierungen oft rückständig sind, sehr nützlich.

Erichsen: Ich möchte auch auf diese Frage gleich antworten. Ich wollte - und dabei gestehe ich zu, Herr Ipsen, daß das ein etwas verzweifelter Versuch ist - einen Orientierungsrahmen auch für die von Thnen soeben angesprochene Kommentarliteratur schaffen. Ob dieser Versuch tauglich ist, kann ich im Augenblick mangels zureichender prognostischer Fähigkeiten nicht beurteilen. Ich meine aber in der Tat, daß die Grundsätze, die ich, u. a. auch in den Thesen 31 und 32, entwickelt habe, insoweit fruchtbar gemacht werden können, zumal sich die Rechtsprechung in einem ganz eigenartigen Zwiespalt befindet, indem sie zum einen bereits nach Maßgabe des von mir Ausgeführten judiziert, zum anderen aber etwa bei der Beurteilung von Aufsichtsmaßnahmen die Utberlegungen, die sich in den Thesen 31 und 32 niedergeschlagen haben, außer acht läßt.

Herzog: Ich möchte zunächst die These von Herrn Knemeyer unterstreichen, daß die Aufgabennormen in den Vordergrund unseres Interesses treten sollten. Bei der Konkretisierung dessen, was damit gemeint ist, befinde ich mich möglicherweise in Nachbarschaft zur Ansicht von Herrn Häberle, daß die Freiheitsrechte das Polizeirecht nicht nur einschränkten, sondern umgekehrt ein Teil der öffentlichen Sicherheit seien, die das 
Polizeirecht zu schützen habe. In dem Bereich der öffentlichen Sicherheit und damit der Normen, die die Aufgaben der Polizei beschreiben, muß die Freiheit dessen, der gestört wird, eine ganz besondere Rolle spielen.

Wir reden ja augenblicklich - so war es bei Herrn Erichsen - immer nur über die Beschränkung der Polizei. Bei Herrn Knemeyer war es in den Thesen 2, 11 und 12 schon etwas anders. Da ist unter der Uberschrift „Anspruch auf polizeiliches Einschreiten" immerhin von der Freiheit dessen, der durch einen anderen in polizeiwidriger Weise beschränkt wird, die Rede. Ich meine, wir sollten diese Tagung nicht vergehen und den Band, der darüber veröffentlicht wird, nicht erscheinen lassen, ohne daß hierauf ein ganz besonderer Akzent gesetzt wird, daß die freiheitssichernde Tendenz des Polizeirechts klargestellt wird, da $B$ der Leistungscharakter dessen - das meine ich nun anders als Herr Erichsen mit der Vermischung mit dem Wohlfahrtsstaat -, was die Polizei tut, herausgestellt wird. Erich Becker hat das schon vor etwa 20 Jahren in dieser Vereinigung gesagt, und ich selbst habe es immer als sehr angenehm empfunden, wenn ich, in irgendeinem Hörsaal mit einer Bande von marodierenden Wanderdemokraten konfrontiert, die Polizei in Sicht gesehen habe.

Das hat positiv-rechtliche Konsequenzen. Die Güterabwägung, in die das Polizeirecht oft hineinführt, wird klarer und leichter, wenn wir auf der einen Seite nicht immer den etwas vagen und auch öffentlich denunzierten Begriff der öffentlichen Sicherheit haben, sondern im Durchgriff sagen können: Hier geht es um den und den Aspekt der Freiheit, der Gesundheit usw. des einzelnen, der geschützt werden soll.

Lassen Sie mich nun am Schluß in aller Stille und in aller Bescheidenheit das Rechtsmittel des flammenden Protestes gegen die Art einlegen, wie heute früh mit geheiligten Begriffen unserer Wissenschaft umgegangen worden ist. Ich will nicht nur das Subsidiaritätsprinzip bei Herrn Knemeyer und nicht nur die Systemtheorie bei Herrn Erichsen nennen, sondern, Herr Knemeyer, unser Erzvater, wenigstens der Erzvater unserer österreichischen Kollegen, Hans Kelsen, dreht sich, wenn ich das recht sehe, seit heute früh pausenlos im Grabe um, nachdem Sie das Wort Grundnorm in Ihrem Sinne verwendet haben.

Martens: Herr Funk hat mich mit seinen einleitenden Bemerkungen zutiefst verunsichert und fast dazu bewogen, meinen Diskussionsbeitrag zurückzuziehen. Er hat dann aber an- 
schließend - wenn ich ihn richtig verstanden habe - gar nicht kritisch vom materiellen Begriff der Polizei gesprochen. Das hat mir den Mut zurückgegeben, ein Wort zur Verteidigung dieses heute morgen kritisierten Begriffs der materiellen Polizei zu sagen. Dies übrigens nicht nur deshalb, Herr Erichsen, weil ich nur ungern öffentlich revidiere, was ich in mühsamer Schreibarbeit zu Papier gebracht habe, bevor es erschienen ist.

Dieser materielle, das heißt von der Aufgabe her bestimmte Begriff der Polizei ist, wenn ich es recht sehe, nach wie vor in den Generalermächtigungen des allgemeinen Polizei- und Ordnungsrechts bzw. des Sicherheitsrechts enthalten, und zwar unabhängig davon, ob in diesen Vorschriften Aufgabenbeschreibung und Befugniszuweisung einheitlich geregelt sind oder auseinanderfallen. Der materielle Begriff der Polizei auch das sollte, wie ich meine, nicht übersehen werden - findet sich darüber hinaus in etlichen Verfassungsbestimmungen, so zum Beispiel in Art. 35 GG.

Was nun den Inhalt dieses materiellen Begriffs und der ihm zugeordneten Aufgabe angeht, so bin ich ganz entschieden der Meinung, daß er sich nach wie vor allein auf die Gefahrenabwehr im herkömmlichen Sinne bezieht. Die gesetzlichen Bestimmungen bis hin zu den limitierten Generalermächtigungen des bayerischen Rechts sind insoweit für mich ganz eindeutig. Diese Bestimmungen beruhen darüber hinaus auf einer rechtsstaatlichen Tradition, von der nicht ohne zwingenden Grund abgewichen werden sollte. Einen solchen zwingenden Grund für eine Abweichung vermag ich nicht zu erkennen.

Lenkende, planende und leistende Verwaltungstätigkeit ist, um mit dem Preußischen Oberverwaltungsgericht zu sprechen, was wohl noch erlaubt ist, auf den Weg der Spezialgesetzgebung zu verweisen. Nur die Spezialgesetzgebung kann, wie ich meine, sachgerechte normative Anforderungen aufstellen, und sie wird auch in der Regel fach- und sachkundige Behörden mit der Aufgabenerfüllung betrauen. Selbst subsidiäre Gefahrenvorsorge, um diesen Terminus aufzugreifen, zum Beispiel zur Verfügung des Polizeivollzugsbeamten oder des Bediensteten der Ordnungsverwaltung zu stellen, würde diese überfordern und die Freiheit der Betroffenen gefährden.

Ich darf zur Bestätigung des Gesagten auf $\S 5$ des BundesImmissionsschutzgesetzes hinweisen, in dem ausdrücklich neben der Gefahrenabwehr zusätzlich von Gefahrenvorsorge entsprechend dem Stand der Technik die Rede ist. Dies geht ebenso über die Gefahrenabwehr im Sinne unserer Generalermächtigungen hinaus wie die zusätzliche Einfügung des Schutzes ge- 
genüber erheblichen Nachteilen und Belästigungen. Ich meine, all das im Sinne vergangener Zeit wieder in die Generalklausel zurückzunehmen, würde im rechtsstaatlichen Gefüge unseres Verwaltungsrechts keinen Fortschritt, sondern einen Rückschritt bedeuten.

Scheuner: Ich habe den Eindruck, daß wir heute, ohne es ganz zu wissen, einer Art stillem Begräbnis beigewohnt haben. Das Polizeirecht ist einmal der Kern des Verwaltungsrechts des liberalen Staates gewesen, und es hat wohl diese seine Position längst überlebt. Im Grunde ist das ältere Polizeirecht der vorliberalen Zeit die Gesamtheit der Verwaltungstätigkeit gewesen, hat darum einen Wohlfahrtsinhalt und damit einen sehr viel weiteren Umfang gehabt, den wir noch bei Mohl oder bei Lorenz von Stein sehen können.

Unser heutiger Polizeibegriff ist eine Schöpfung von 1881. Er umfaßt also erst eine verhältnismäßig späte Zone des 19 . Jahrhunderts. Er ist insofern am Ende, als sein Gebiet, so etwa wie bei einem Eisbecher, der in der Sonne steht, dahingeschmolzen ist. Im Grunde sind die wirklich wesentlichen Fragen heute nicht mehr vom Polizeirecht geregelt, sondern von Spezialgesetzen. Was Herr Martens verlangt, ist längst geschehen. Diese Spezialgesetze - das hat Herr Erichsen, glaube ich, ganz richtig gezeigt - haben mehr wohlfahrtsstaatliche Inhalte - Sie haben selbst schon beim Immissionsschutzgesetz darauf aufmerksam gemacht - als die allgemeine Ermächtigung. Wenn wir also auch die allgemeine Ermächtigung als reine Gefahrenabwehr verteidigen, so verteidigen wir nur noch ein sehr schmales Gebiet, das dem allgemeinen Polizeirecht überhaupt verblieben ist. Daß es im Unterricht einen so weiten Raum einnimmt, gehört zu den Altertümlichkeiten unseres Rechtsunterrichts, die man hinnehmen muß.

Ich meine, um Herrn Ipsen zu antworten, das Wirtschaftsrecht sei längst aus dem Polizeirecht herausgetreten. Wenn es in der Schweiz noch im Polizeirecht steht, so hat Herr Eichenberger uns mit Recht darauf aufmerksam gemacht, wie schwierig die kantonale Gesetzgebung in diesen Dingen ist, daß sich das aus einer aus verfassungsrechtlichen Gründen bestehenden Situation erklärt, aber nicht eine aus inneren Gründen abweichende Situation aufzeigt. Ich glaube daher, daß wir ganz recht tun, wenn wir das Polizeirecht einschränkend betrachten. Es sind allerdings gleichzeitig ein paar Nägel zu dem Sarge, in dem wir es allmählich einsargen. Denn etwa die Vorstellung, $\mathrm{da} \beta$ das Atomgesetz in immer weiterer Gesetzesbindung enden 
würde, daß jede Opportunität aufhört, wird natürlich den $\mathrm{Ge}-$ setzgeber veranlassen müssen, die Maßstäbe zu senken, wenn er überhaupt noch ein Atomkraftwerk zu Boden bringen will. Ähnlich wird es auf anderen Gebieten gehen. Je mehr wir glauben, daß das Ideal der Verwaltung der Steuerbescheid ist, der ganz streng rechtlich ohne irgendeine Gestaltungsmöglichkeit der Verwaltung ergeht, desto mehr werden wir eine neue Spezialgesetzgebung hervorrufen, die dann die nötigen inhaltlichen Maßstäbe setzt.

Hier darf ich vielleicht eine kleine Bemerkung einschalten, die dem Notruf einiger unserer Kollegen entspricht, den wir soeben gehört haben. Beide Referenten haben sich in verdienstvoller Weise bemüht, die Abstraktion der Verwaltung in der Hervorhebung der wirklich grundsätzlichen Dinge zu betreiben. Ich meine, daß das ein sehr löbliches Unterfangen ist, daß man aber zugleich auch einen Fuß in den praktischen Fällen und Beispielen behalten sollte.

Ich habe es anerkannt, daß man in beiden Referaten versucht hat, solche Beispiele zu geben, aber ich hätte etwa die dreifache Zahl von ihnen begrüßt. Ich meine auch, daß wir in unserer Vereinigung vielleicht danach streben sollten, die modernen Slangs anderer Disziplinen bei uns nicht einzuführen. Das einfache gute Deutsch ist immer noch die klarste Darbietung und auch die Art, in der man Dinge so ausdrückt, daß man sie nicht bloß verstehen kann, sondern da $\beta$ auch die inhaltlichen Fragen wirklich umschrieben werden, ohne daß ich damit den Parameter der glanzvollen Diktion einengen will.

Ich wollte am Schluß nur noch eine Bemerkung machen. Ich glaube, daß die Behandlung durch beide Referenten eine spezifische Gefahr aufgezeigt hat: Die Tendenz, das Verwaltungsrecht fast nur noch - Herr Knemeyer hat hierzu eine sehr richtige kritische Bemerkung gemacht - aus den Grundrechten abzuleiten, scheint mir kein glücklicher Ansatz. Die Grundrechte sind gewiß Schranken des Verwaltungsrechts, sie sind - darin stimme ich mit Herrn Häberle überein - gelegentlich Aufträge an die Verwaltung, aber wir sollten nicht das ganze Verwaltungsrecht aus den Grundrechten ableiten. Wir sollten uns klarmachen, daß in der Verwaltung praktische Lebensverhältnisse zu gestalten sind, die wohl den Rahmen der Verfassung einhalten müssen und in ihn eingebaut sind, die aber jedenfalls nicht allein aus grundrechtlichen Freiheiten, Kollisionen von Grundrechten abzuleiten sind. Sonst kommen wir dahin, was sich in der Bundesverfassungsgerichtsbarkeit schon abzeichnet, daß wir ein Grundrecht bejahen, dann aber zu- 
schauen und im Kompetenzkatalog suchen, bis wir irgend etwas finden, um dann daraus eine Schranke des Grundrechts ableiten zu können.

Knemeyer: Herr Scheuner, nur einen Satz dazu. Sie sagten, Sie hätten die dreifache Zahl von Beispielen begrüßt. Ich darf sicher für Herrn Erichsen mitsprechen: Wir hätten gerne die fünffache Zahl gebracht, um das, was wir hier vorgetragen haben, zu illustrieren.

Erichsen: Ich darf mich in diesem Augenblick auf eine kurze Bemerkung zur Begrifflichkeit beschränken: Der sehr verehrte Herr Vorsitzende hat mich bereits heute morgen als Anhänger der Systemtheorie qualifiziert. Das möchte ich für mich nicht in Anspruch nehmen. Ich habe nur geglaubt, daß man vielleicht mit den verwandten Begriffen einiges deutlicher machen könnte. Es war keinesfalls mein Anliegen, diese Begriffe gewissermaßen als Deduktionsarsenale in das Ordnungsund Polizeirecht einzuführen, sondern ich wollte sie eigentlich eher deskriptiv und kompilatorisch verwendet haben, um gerafft Befunde $\mathrm{zu}$ umschreiben, die ich vorher im einzelnen entwickelt hatte.

Zuleeg: Ich stimme Herrn Scheuner grundsätzlich zu, daß wir das Verwaltungsrecht nicht aus den Grundrechten konstruieren sollten. Aber bei allem Respekt vor dem geschlossenen und meines Erachtens auch einleuchtenden System, das Sie, Herr Erichsen, vor uns aufgebaut haben, glaube ich doch, daß die Grundrechtsbindung bis zu einem gewissen Grade vernachlässigt worden ist. Einmal entwickeln Sie im Anschluß an die Rechtsprechung des Bundesverfassungsgerichts zu den verfassungsimmanenten Schranken eine Begrenzung der Grundrechte durch die öffentliche Sicherheit, und zwar auch zugunsten der Individualgüter. Versteht man nun, wie Sie es auch einmal erwähnt haben, unter der öffentlichen Sicherheit die gesamte Rechtsordnung, müßte man doch eigentlich zu dem Schluß kommen, daß die Grundrechte dem einfachen Gesetzgeber ausgeliefert sind.

Ich bin sicher, daß Sie diese Folgerung nicht ziehen wollen, möchte aber daran die Frage anschließen: Wo sind die Grenzen, wenn man diese Folgerung nicht ziehen will?

Zweiter Punkt: Bei der öffentlichen Ordnung greifen Sie, wie einige Diskussionsredner auch, auf die gesellschaftlichen Auffassungen zurück. Sie sehen den einzigen Anhaltspunkt für 
Bedenken aus der Verfassung im Bestimmtheitsgrundsatz. Ich meine, daß die Bedenken berechtigt sind, vor allem aus dem Gesichtspunkt heraus, daß sich nicht genau ermitteln läßt, was nun eigentlich die gesellschaftlichen Auffassungen sind.

Aber ich meine, man muß auch Bedenken haben aus dem Gesichtspunkt der demokratischen Legitimation und aus dem Gesichtspunkt des Gleichheitssatzes heraus, wenn also etwa von Polizeirevier zu Polizeirevier die Anschauungen verschieden sein sollten.

Allerdings den Schluß zu ziehen, daß die Klausel „öffentliche Ordnung" deswegen verfassungswidrig sei, würde insoweit schon sonderbar anmuten, als Art. 13 GG die Klausel sogar ausdrücklich übernimmt.

Deshalb ist die einzige Möglichkeit, eine verfassungskonforme Auslegung zu finden, Sie haben selbst ein Stichwort dazu geliefert: die Regelung des Verhältnisses der Bürger untereinander. Bei Herrn Eichenberger ist ausdrücklich das Stichwort der Drittwirkung der Grundrechte gefallen.

Ich meine, man sollte und kann die öffentliche Ordnung verfassungskonform nur so verstehen, daß hier die Grundrechtsbindungen im Verhältnis der Bürger untereinander konkretisiert werden.

Friauf: Beide Herren Referenten haben uns sehr eindrucksvoll vor Augen geführt, daß das Polizeirecht - dem Anschein nach ein Rechtsbereich von ungebrochener Tradition - heute ein Recht im Umbruch ist. Im weiten Bereich unseres öffentlichen Rechts finden wir kaum ein anderes Gebiet, dessen normativer Bestand im gleichen Maße wie der des Polizeirechts in der ungebrochenen Tradition des 19. Jahrhunderts und der Positivierungen aus der Zeit der Weimarer Republik verharrt.

Hinter dem Schleier dieser ungebrochenen Tradition der normativen Ordnung hat jedoch ein tiefgreifender Wandlungsprozeß eingesetzt. Er wurde dadurch ausgelöst, daß das normativ unveränderte Polizeirecht heute in einem grundlegend gewandelten verfassungsrechtlichen Zusammenhang steht und daß es zudem vielfach auf neuartige tatsächliche Anforderungen zu reagieren hat. Um es auf eine Kurzformel zu bringen: Die Normen des tradierten Polizeirechts sind zugeschnitten auf ein sozioökonomisches System, das statisch auf Bewahrung und Neutralisierung der gesellschaftlichen Ordnung ausgerichtet war. Die vornehmliche Aufgabe des Polizeirechts bestand darin, diese Neutralisierung ("Störungsneutralität") zu gewährleisten und systemwidrige - und damit "polizeiwidrige" - 
Störungen im Einzelfall zu unterdrücken bzw. zu reparieren. Demgegenüber befindet sich das Polizeirecht heute in einer verfassungsrechtlichen wie rechtstatsächlichen Umgebung, in der der Staat seinen Auftrag in erster Linie nicht mehr allein darin sieht, zu bewahren und zu neutralisieren, sondern wo vor allem gefördert, geleistet, gestaltet und fortentwickelt werden soll.

Dieser Grundwiderspruch zwischen der statischen, auf Bewahrung angelegten Ordnung des Polizeirechts auf der einen Seite und dem neuen Verständnis des staatlichen Auftrags sowie der entscheidend gewandelten sozialen Wirklichkeit auf der anderen Seite bildet die eigentliche Krux, aus der die zahlreichen Probleme hervorgehen, die uns heute im Polizei- und Ordnungsrecht auf den Nägeln brennen.

Das tradierte Polizeirecht muß in Anbetracht der neuen Anforderungen fortentwickelt werden. Beide Referenten haben dazu wesentliche Ausführungen gemacht. Wir sollten uns aber stets bewußt bleiben, daß die Anpassungsfähigkeit der polizeirechtlichen Instrumente durchaus begrenzt ist. Ich möchte deshalb mit Herrn Martens hier insoweit zu Vorsicht mahnen. Es wäre aus rechtsstaatlichen Gründen schlechterdings unerträglich, wenn man durch eine inhaltliche Umwertung der polizeirechtlichen Eingriffsermächtigungen $\mathrm{zu}$ einer verkappten "Wohlfahrtspflege" in neuem Gewand käme und damit letztlich wieder auf die Ebene des alten Polizeistaates zurückfiele. Ein Schritt hinter das Kreuzberg-Urteil zurück, den man etwa mit dem Sozialstaatsprinzip rechtfertigen wollte, erscheint unmöglich. Dafür sind die Waffen des Polizeirechts zu scharf und die Generalklauseln zu unbestimmt.

Noch ein paar konkrete Bemerkungen zu den Einzelpunkten: In der Frage der Beibehaltung des materiellen Polizeibegriffs möchte ich mich voll Herrn Martens anschließen. Als norminspizierendes Prinzip sollte er sicher aus der Diskussion verschwinden können. Aber als Prinzip der Normauslegung scheint er mir nach wie vor nicht nur sinnvoll, sondern unverzichtbar zu sein.

Mit Genugtuung habe ich gehört, daß Herr Erichsen entgegen gewichtigen Strömungen im neueren Schrifttum grundsätzlich am Schutzgut der öffentlichen Ordnung festhält und daß er - darin sehe ich einen wesentlichen Fortschritt - ein abgewogenes System des Ausgleichs zwischen den Grundrechten auf der einen Seite und der öffentlichen Ordnung auf der anderen Seite vorgestellt hat. Die Thesen 14 und 15 scheinen mir insofern überzeugend und ausgewogen. Nur muß man sich 
bewußt sein, daß das Schutzgut der öffentlichen Ordnung seine frühere umfassende Bedeutung nicht wieder wird erlangen können. Sein Anwendungsbereich ist aus zwei Gründen eingeengt: einmal wegen der heute sehr viel weiterreichenden positiv-gesetzlichen Regelungen, die frühere Sphären der öffentlichen Ordnung durch ausdrücklichen Ausspruch des Gesetzgebers abgedeckt haben und als leges speciales dem Polizeirecht vorgehen, und zum anderen durch die Tatsache, daß der innergesellschaftliche Minimalkonsens - denn das ist der Bereich der öffentlichen Ordnung - in den letzten Jahrzehnten sehr stark reduziert worden ist.

Es ist deshalb kein Wunder, daß es schwerfällt, in der neueren Rechtsprechung Beispiele für die Anwendung der öffentlichen Ordnung zu finden. Am ehesten stößt man noch auf die nicht ganz appetitlichen Bordellfälle. Ich habe allerdings den Verdacht, daß die verwaltungsgerichtliche Judikatur in dieser Frage kein wirklich repräsentatives Bild der Verwaltungspraxis liefert. Wir geraten (nicht nur hier) leicht in die Gefahr von Fehlschlüssen, wenn wir uns vom grünen Tische des Verwaltungsjuristen aus allzu einseitig an der Judikatur orientieren und dahinter die Verwaltungswirklichkeit nicht hinreichend in den Griff bekommen. Gewiß wäre es des Schweißes der Edlen, vielleicht eines Doktoranden, wert, einmal eine Feldstudie über die Frage durchzuführen, wie die öffentliche Ordnung in der Verwaltungspraxis gehandhabt wird.

Trotz der Verengung des Anwendungsbereichs der öffentlichen Ordnung möchte ich aber dezidiert daran festhalten, daß dieses Schutzgut auch in Zukunft unverzichtbar bleibt. Wir benötigen es als eine Art fleet in being, um den notwendigen Mindeststandard an gemeinverträglichem Verhalten innerhalb der Gesellschaft zu garantieren, ohne den es keinen inneren Frieden geben kann.

In der Frage der Wandlungsoffenheit der öffentlichen Ordnung stimme ich Herrn Häberle grundsätzlich zu. Dieses Schutzgut ist schon per definitionem auf dynamische Änderungen angelegt.

Der innergesellschaftliche Konsens, aus dem die öffentliche Ordnung hervorgeht, befindet sich in permanenter Weiterentwicklung. Gleichwohl ist in diesem Zusammenhang aber besondere Vorsicht geboten. Wie immer der Kanon von gemeinschaftlichen Uberzeugungen der Rechtsgenossen aussehen mag, der auf einer bestimmten Stufe der Entwicklung den Inhalt der öffentlichen Ordnung ausmacht: Es kann und darf sich immer nur um einen Minimalkonsens handeln. Unter keinen 
Umständen darf der Schutz der öffentlichen Ordnung zu einem neuen Totalitarismus irgendeiner Meinungsrichtung entarten.

Skeptisch bin ich gegenüber den Ausweitungen, die Herr Erichsen in den Thesen 7 und 8 versucht hat. Nach meiner Uberzeugung darf die Generalklausel auch nicht auf einem solchen argumentatorischen Umweg als Ansatzpunkt für eine neue Methode der Wohlfahrtspflege verwendet werden. Nicht nur der rechtsstaatlich gebotene Individualschutz, sondern auch die Prärogative des demokratischen Gesetzgebers stehen dem entgegen.

Noch ein letzter Satz: Gegenüber einigen Andeutungen in den Referaten möchte ich strikt am „Offentlichkeitsbezug" der polizeilichen Gefahrenabwehr festhalten. Eine Gefährdung von Individualgütern, die nicht in die Offentlichkeit ausstrahlt und demzufolge keinen Offentlichkeitsbezug aufweist, sollte grundsätzlich außerhalb der polizeilichen Eingriffskompetenz bleiben. Die Privatsphäre des Bürgers ist auch in dieser Hinsicht polizeifest.

Mußgnug: Eigentlich wollte ich zu einigen grundsätzlichen theoretischen Ausführungen anheben und mich dabei zwischendurch auch fremder Sprachen bedienen. Aber Herr Scheuner hat mir leider den Schneid abgekauft, den dieses Unterfangen voraussetzt. Deshalb möchte ich bescheiden bleiben und nur an Herrn Friauf anknüpfen, der uns aufgefordert hat, nach sittlich einwandfreien Beispielen für die Sinnhaftigkeit des Begriffs der öffentlichen Ordnung zu suchen. Ich habe ein solches moralisch sauberes Beispiel anzubieten, das mir die sichere Gewißheit verschafft hat, daß die öffentliche Ordnung keineswegs als die „Verbindung Hegelschen Vernunftobjektivismusses mit dem monarchischen Quietismus der Restaurationsepoche" abgetan werden kann, wie das Herr Denninger vor einigen Jahren in seiner Schrift „Polizei in der freiheitlichen Demokratie" versucht hat.

Mit Hegel hat allerdings auch mein Beispiel zu tun. Denn es spielt in Bamberg. Dort habe ich vor geraumer Zeit den Dom besucht, als gerade kein Gottesdienst stattfand, der den Sachverhalt dank des $\S 167$ StGB der öffentlichen Ordnung entrückt und auf den festeren Boden der öffentlichen Sicherheit gestellt hätte. Zugleich mit mir war auch eine junge Dame mit einem entzückenden Zwergpudel in das Gotteshaus gekommen. $\mathrm{Da}$ sie nur den Hund, aber keine Leine mitgebracht hatte, konnte das Tier munter im Kirchenschiff auf und ab springen. In der Heiliggeist-Kirche in Heidelberg hätte ihm die Polizei 
das ohne größere Umstände verwehren können. Denn sie hätte seiner Herrin nur interdisziplinär argumentierend den polizeilichen Begriff der öffentlichen Ordnung und einige in die Landessprache der Kurpfalz übersetzte psychiatrische Grundbegriffe entgegenzuhalten brauchen. Das hätte im Geltungsbereich des baden-württembergischen Polizeirechts zur Verbannung des Pudels aus der Kirche vollauf ausgereicht. In Bamberg indessen, wo es die öffentliche Ordnung nach alter bayerischer Tradition nicht gibt, gestaltete sich die Rechtslage komplizierter. Hier mußte ein Küster herbeigeschafft werden. Erst als dieser gefunden war und die für einen Hausfriedensbruch erforderlichen Erklärungen abgegeben hatte, konnte sich auch die Bamberger Polizei gegenüber dem Pudel durchsetzen. Wäre sie nicht nur zur Verteidigung der öffentlichen Sicherheit, sondern auch zum Schutze der öffentlichen Ordnung ermächtigt gewesen, so hätte sie sich einfacher behaupten können, ohne den Küster in seiner wohlverdienten Mittagsruhe stören zu müssen. Darin liegt m. E. der Beweis, daß man die öffentliche Ordnung nicht verachten sollte.

Einen weiteren schlagkräftigen Beweis dafür liefert nach meiner Utberzeugung auch der von Herrn Erichsen bemühte Fußballspieler vom Dienst, den die Polizei immer wieder samstags ins Fernsehstudio chauffiert. Ich bin zwar kein Anhänger des Fußballs, glaube aber dennoch, daß die Aufgabe, Fußballstars bei der Einhaltung ihrer Terminverpflichtungen zu helfen, mit zur Pflege der öffentlichen Ordnung gehört, der sich die Polizei anzunehmen hat.

Die Polizei kutschiert im übrigen nicht nur Fußballspieler. Ich entsinne mich an Berichte, denen zufolge Brautpaare, die im Verkehrsstau steckengeblieben waren, von der Polizei mit Blaulicht und Martinshorn noch rechtzeitig zum Standesamt gebracht wurden. Ebenso sind Ärzte in den Operationssaal, Pfarrer zur Kirche und Sänger zur Premiere gefahren worden.

Das gehört nach meiner Uberzeugung deshalb zur polizeilichen Ordnungspflege, weil die Polizei mit diesen Hilfsdiensten garantiert, daß selbst in Zeiten, in denen der Straßenverkehr nicht mehr funktioniert, besonders wichtige, förderungswürdige menschliche Anliegen pünktlich realisiert werden können, die ohne das unterstützende Eingreifen der Polizei am Verkehrschaos (mit andern Worten also an der öffentlichen Unordnung) scheitern würden.

$\mathrm{Da}$ auch das zu den legitimen Polizeiaufgaben gehört, steht m. E. außer Zweifel. Zweifelhaft kann allenfalls sein, ob auch der allsamstagliche Fernsehauftritt des Fußballspielers vom 
Dienst für das kulturstaatliche Gepräge der Bundesrepublik so wichtig ist, daß die öffentliche Ordnung gestört wäre, wenn er ausnahmsweise einmal ausfallen müßte. Bei Brautpaaren, Ärzten, Pfarrern, Sängern und auch bei Professoren, die zur Vorlesung eilen, sehe ich indessen keine Bedenken.

Was mich in diesem Zusammenhang beschäftigt, ist allerdings weniger die Frage, ob die Polizei auch Fuhrdienste leisten darf, dafür aber um so mehr das daran anknüpfende ganz andere Problem, wer die Kosten solcher polizeilicher Hilfsdienste zu tragen hat. Denn es geht nicht nur um den verhältnismäßig billigen Transport einzelner Fußballspieler zum Fernsehstudio. In Städten, die mit einem Bundesligaverein gesegnet sind, hat die Polizei sehr viel mehr zu tun. Hier muß sie alle vierzehn Tage den Fußballvereinen tausende von zahlenden Zuschauern pünktlich in die Stadien lenken, um sie nach dem Abpfiff wieder rasch und sicher nach Hause geleiten zu müssen. Das bereitet ihr sehr viel kostspieligere Aufwendungen als ihre gelegentlichen Fuhrdienste. Es liegt sehr nahe, diejenigen, denen der Nutzen dieser Aufwendungen zufließt, um Erstattung $\mathrm{zu}$ bitten. Aber das ist ohne besondere gesetzliche Grundlage nicht zu machen. Denn wer ein Fußballspiel oder ein Konzert veranstaltet, ist nicht Störer. Er übt vielmehr eine erlaubte Tätigkeit aus. Folgt daraus, daß ein solcher Veranstalter die Kosten, die er der Polizei verursacht, bereits durch seine Steuerzahlungen abgegolten hat? Oder ist es gerechtfertigt, so zu verfahren, wie es das baden-württembergische Polizeigesetz in seinem $\S 81$ Abs. 2 getan hat? Diese Vorschrift sieht vor, daß der Polizeieinsatz bei privaten Veranstaltungen zu bezahlen ist, jedoch nur dann, wenn mehr Beamte eingesetzt werden müssen, als am Orte zur Verfügung stehen, also nur dann, wenn die Bereitschaftspolizei zur Verstärkung herbeigeholt werden muß. Aus diesem Grunde funktioniert $\S 81$ Abs. 2 des badenwürttembergischen Polizeigesetzes nicht. Denn in aller Regel kommt die Polizei mit ihren lokalen Kräften aus, und das heißt: Ihr Einsatz muß selbst dann, wenn er über alle Maßen aufwendig ist, von der Staatskasse getragen werden, ohne daß die Veranstalter, die dank der Hilfe der Polizei erhebliche Summen einstreichen können, sich an den Kosten zu beteiligen brauchen.

Mich enttäuscht, daß der Entwurf des Polizeigesetzes dieses Problem nicht bedacht hat. Ich halte es für sehr wichtig und auch zukunftsträchtig. 
Wilke: Ich möchte zwei Bemerkungen machen, und zwar erstens zu dem von Herrn Erichsen beklagten Abgleiten der polizeilichen Sondergesetze sozusagen ins Abseits. - These 2: Sie bedauern dort die zunehmende Isolierung und den strukturellen Eigenwuchs besonderer Polizeirechtsgebiete und der ihnen zugeordneten Organisationseinheiten.

Nun ist es gewiß angenehm, mit einem Gesetz zu hantieren und nicht eine Fülle von Gesetzen zu verwenden. Ferner ist es sicherlich sinnvoll, an den Gesetzgeber und an den Wissenschaftler zu appellieren, bei der Betrachtung verwandter Rechtsgebiete die Verwandtschaft zu berücksichtigen, etwa in der Rechtsterminologie oder in der Rechtstechnik. Ich habe aber den Eindruck, Herr Erichsen, daß Sie in dieser Separation oder Emanzipation des besonderen Polizeirechtes Gefahren sehen. Diese Vermutung hat sich in mir dadurch erhoben, da $B$ Sie die an sich hübsche Formulierung gewählt haben, das „Gesamt der Verfassung" sei wohl am besten im allgemeinen Polizeirecht und bei den Behörden, die für die Betreuung des allgemeinen Polizeirechts zuständig sind, aufgehoben.

Diese These halte ich nicht für richtig! Ich würde meinen, daß das Ensemble der Verfassung bei Spezialbehörden genauso gut aufgehoben ist und daß diese durchaus in der Lage sind, die Verfassung insgesamt $\mathrm{zu}$ überblicken und zu berücksichtigen. Ich möchte sogar die Gegenthese aufstellen: Je mehr sich der Sondergesetzgeber vom allgemeinen Polizeirecht löst, je detaillierter er seine Spezialgesetze faßt und je weniger er die Rückbindung an das allgemeine Polizeirecht durchführt, umso größer ist die Wahrscheinlichkeit, daß beim Vollzug dieser sehr detaillierten und umfangreichen Gesetze die Konformität mit der Verfassung gewährleistet ist. Also die These: Wenn der Gesetzgeber sich vom allgemeinen Polizeirecht löst, dann soll er es total tun und sich nicht mit Fragmenten begnügen.

$\mathrm{Zu}$ welchen kuriosen Ergebnissen man kommt, wenn der Gesetzgeber nur Teilbereiche regelt und es im übrigen den Exekutoren überläßt, auf das allgemeine Polizeirecht zurückzugreifen, wird an Ihrem Beispiel besonders deutlich. Sie haben die nordrhein-westfälische Rechtslage so geschildert: Nach der dortigen Bauordnung ist eine Abrißverfügung wohl nicht ohne weiteres möglich, sondern der Rekurs auf das allgemeine Polizei- und Ordnungsrecht ist vonnöten. Wie ist es bei der Abrißverfügung? Nach der Rechtslage in Nordrhein-Westfalen ist die Bauaufsichtsbehörde berechtigt, bei der therlegung, ob ein Abriß eines Gebäudes vonnöten ist, arbeitsmarktpolitische und sonstige wirtschaftspolitische Erwägungen anzustellen. Das 
scheint mir sehr unangebracht. Ich würde sagen: Wenn der Bauordnungsgesetzgeber von Nordrhein-Westfalen sich der Regelung des Baurechts annimmt, dann soll er es total tun. Er hätte die Frage des Abrisses mit regeln sollen, und dann hätte er sie vernünftigerweise so geregelt, daß die Abrißvoraussetzungen ausschlieBlich sicherheitspolizeiliche, baurechtliche Voraussetzungen sind. Denn es kann ja nicht sinnvoll sein, bei der Gefährdung derart hochwichtiger Rechtsgüter Arbeitsmarkterwägungen mit einfließen zu lassen. Was nützt es dem Arbeitnehmer, wenn er zusammen mit seinem Arbeitsplatz unter den Ruinen des Gebäudes liegt?

Eine zweite Bemerkung: Sie haben konstatiert, meines Erachtens sogar propagiert, eine Aufladung oder tberladung und Uberforderung des allgemeinen und des besonderen Polizeirechts mit neuen Aufgaben und neuen Rechtsgütern: These 8 und These 33.

Für die These 33 haben Sie die prägnante Formulierung gefunden, private Rechtsgüter müßten einem Prozeß der „Veröffentlichung" unterworfen werden. Das ist sicherlich als Konstatierung teilweise zutreffend, aber als rechtspolitisches Konzept, sozusagen als Anregung an den Gesetzgeber, auf diesem Wege fortzufahren, höchst bedenklich. Ich will es wiederum am Baurecht demonstrieren.

Das Baurecht hat in der Tat im Laufe der letzten Jahre und Jahrzehnte neue Rechtsgüter in sich aufgesaugt und wird neuerdings auch in den Dienst der Wohlfahrtspflege genommen. Allerdings würde ich die Berücksichtigung planungsrechtlicher Aspekte nicht zur Wohlfahrtspflege rechnen, sondern das läßt sich doch auch mit den Mitteln des klassischen Polizeirechts erklären. Wenn die Bauaufsichtsbehörde planungsrechtliche Erwägungen anstellt, dann sorgt sie dafür, daß die öffentliche Sicherheit gewahrt wird.

Aber wie dem auch sei: Es gibt echte Wohlfahrtsaspekte im neuen Baurecht: Energiespargesetz und ein weiteres Beispiel aus der hessischen oder niedersächsischen Bauordnung: Der Bauherr wird verpflichtet, Freizeiteinrichtungen für seine Mieter bereitzustellen.

Der Effekt, den derartige modische Rechtsgüter im Bereich Bauverwaltung nach sich ziehen, ist folgender: Die Bauverwaltung wird verdrossen, ist völlig überfordert, sucht nach Abhilfe, führt contra legem die ihr neu zugewiesenen Aufgaben effektiv gar nicht aus. Mir ist jetzt bekanntgeworden, da $B$ in der Bauverwaltung immer mehr der Ruf nicht nach der weiteren „Veröffentlichung“ von Rechtsgütern erschallt, son- 
dern der Ruf nach der Privatisierung. Die überlastete Bauverwaltung sucht nach Mitteln, um Aufgaben auf Private zu delegieren, entweder im Wege der Heranziehung beliehener Unternehmer oder etwa im Wege der weiteren Benutzung privatrechtlicher Formen, z. B. durch Ausbau des Nachbarrechts.

Ich warne vor dem Weitergehen auf diesem Weg. Das ist kein Regelkreis, sondern ein Teufelskreis.

Erichsen: Herr Wilke, ich habe Zweifel, ob das, was Sie hier vorgetragen haben, so ganz in sich schlüssig ist. Einerseits fordern Sie möglichst viele Sondergesetze. Andererseits plädieren Sie dafür, statt der Sondergesetze privatrechtliche Regelungen zu erlassen.

(Wilke: Wenn Gesetze, dann Sondergesetze!) ist.

- Ich sehe nicht ganz, wie das auf einen Nenner zu bringen

Was das Problem der Sonderbürokratien - um es einmal schlagwortartig aufzunehmen - betrifft, so sehe ich in der Tat eine gewisse Gefahr. Natürlich sehe ich auch die Vorteile der sondergesetzlichen Regelung; mir ging es indes darum, den Blick auf die damit verbundenen, in der Verwaltungswissenschaft bisher kaum bedachten Probleme dieser Entwicklung zu lenken. Es bedarf wohl einer gewissen Feldforschung, um einmal festzustellen, wieweit der Befund, den ich nur aus eigener und sehr begrenzter Anschauung erheben konnte, zutrifft, daß die sondergesetzliche Regelung von Lebensbereichen $\mathbf{z u}$ einer Verselbständigung von Organisations- und Aktionsstrukturen führt und daß es zu einer fehlenden Rückbindung an das Gesamte der Verfassung und an das allgemeine Verwaltungsrecht kommt. Mir jedenfalls erscheint es denkbar, daß wir wieder zu einem Verständnis der Staatsgewalt kommen, welches nicht mehr durch das die Organisations- und Kontrollstrukturen unseres Staates prägende Prinzip der Einheit der Staatsgewalt gekennzeichnet ist, sondern auf eine hoheitsrechtliche Betrachtungsweise hinausläuft, wie sie in früheren Zeiten einmal herrschend gewesen ist.

Götz: In unserer bisherigen Diskussion war Herr Mußgnug der erste und einzige, der sich auch die Frage gestellt hat, was denn das alles kostet. Er hat dazu die Rechtsfrage gestellt, ob denn die Großveranstalter, vor allem die von Fußballveranstaltungen, für den polizeilichen Schutz, der sich als polizeiliche Förderung erweist, auch zahlen müßten. Freundlicherweise hat Herr Mußgnug diese Frage für das baden-württembergische Recht auch gleich beantwortet. Darf ich noch ergän- 
zen: Auch in Hessen finden sich die entsprechenden Rechtsgrundlagen für eine Zahlungspflicht; in den übrigen Ländern aber nicht.

Obwohl der Stand unserer Diskussion, wie die von Herrn Mußgnug aufgeworfene Kostenfrage zeigt, schon sehr fortgeschritten ist, möchte ich aber doch noch einmal auf die Grundpositionen der beiden Referenten eingehen.

Die Grundpositionen beider Referenten, ihre Grundauffassungen zu dem, was Polizei- und Ordnungsrecht heute ist, stimmen in einem so hohen Maß mit den meinigen überein, daß ich dies nur erfreut feststellen kann. Ich glaube, daß beide Referenten den richtigen Ansatzpunkt gewählt haben, von dem aus nur man zu zutreffenden Vorstellungen über den Bestand und die Funktionen des heutigen Polizei- und Ordnungsrechtes kommen kann, nämlich den Ansatz bei den spezialgesetzlichen Ermächtigungen der Exekutive. Das heißt: Die beiden Referenten haben anders, als dies weithin üblich ist, den Blick nicht wie gebannt nur auf die Generalermächtigung gerichtet, sondern haben in höchst förderlicher Weise ihre Aussagen zum Polizei- und Ordnungsrecht an der Spezialgesetzgebung orientiert.

Wer - um ein paar Beispiele zu nennen - Ausländerrecht, Arzneimittelrecht, Atomenergierecht, Gesundheitsschutz, Gewerberecht, Lebensmittelrecht, Baurecht, Verkehrsrecht zur Kenntnis nimmt und als Erkenntnisgegenstand auch ernst nimmt, der kann nicht mehr zu der Feststellung kommen, daß im Polizei- und Ordnungsrecht alles wie bisher sei und wir beim überkommenen Polizeibegriff heute nach wie vor stehenbleiben könnten, sondern muß zu den Folgerungen kommen, zu denen Herr Erichsen und Herr Knemeyer gekommen sind.

Um diesen Ansatz der beiden Referate und seine grundlegende Bedeutung noch einmal hervorzuheben, weise ich darauf hin, daß das Thema der spezialgesetzlichen Ermächtigungen bei Herrn Erichsen bereits in der These 1 anklingt und dann in einem großen Bogen zur These 33 geschlagen wird, und daß Herr Knemeyer über Baurecht, Immissionsschutzrecht und Atomenergierecht gesprochen hat.

Wenn wir diese spezialgesetzlichen Ermächtigungen im Blick behalten, dann erscheint mir auch die grundlegende These 3 von Herrn Erichsen richtig, in der er vom Verhältnis von Gefahrenabwehr und Wohlfahrtspflege handelt. Er sagt hier, beides sei nicht eindeutig zu trennen. Eine Feststellung, die ich gerne unterstreichen möchte. Gleichwohl sind aber Gefahrenabwehr und Wohlfahrtspflege immer noch als Modelle zu unterscheiden, und zum zweiten sind sie auch im Recht in unter- 
schiedlicher Weise ausgeformt und in durchaus unterschiedlicher Weise der Verwaltung als Aufgabe und Handlungsermächtigung aufgegeben.

Ich glaube allerdings, daß Sie, Herr Erichsen, erläutern sollten, ob Ihre These 8 sich nur auf die Aufgabenzuweisung erstreckt und dasjenige, was der Verwaltung im Rahmen dieser Aufgabenzuweisung an Tätigkeit möglich ist, oder ob Sie diese These auch auf die Befugnisnormen und die Eingriffe in individuelle Freiheiten und Rechte erstrecken.

Ich glaube nicht, da $\beta$ die These 3 von Herrn Erichsen in irgendeiner Weise so gedeutet werden sollte, daß sie als Einbeziehung der Wohlfahrtszwecke in den Polizeibegriff zu verstehen ist. Herr Erichsen arbeitet ja gerade nicht mehr mit einem Polizeibegriff, sondern stellt unterschiedlich ausgestaltete Zwecksetzungen und Aufgaben in verschiedenen Bereichen unseres Verwaltungsrechtes fest. Einen Schritt hinter Kreuzberg zurück vermag ich in keiner Weise zu erblicken.

$\mathrm{Da}$ ich eine Zeitmahnung bekommen habe, versage ich mir Bemerkungen zur "öffentlichen Ordnung“, die ja auch in diesem Zusammenhang gar kein solch entscheidendes Gewicht hat.

Fromont: Zwei kurze Bemerkungen. Erstens habe ich den Eindruck, daß die allgemeinen Polizeibefugnisse mit der Souveränität des Staates schlechthin eng verbunden sind. Ich glaube, daß ein Staat ohne allgemeine Polizei undenkbar wäre. Als Beispiel könnte man eine ältere Entscheidung des französischen Conseil d'Etat erwähnen. In diesem Fall hatte der Conseil d'Etat dem Präsidenten der Republik - es war in der Zeit der Dritten Republik - eine Polizeibefugnis ohne gesetzliche Grundlage zuerkannt.

Die zweite Bemerkung, die damit verbunden ist, ist die folgende:

Die allgemeinen Polizeibefugnisse sind besonders wichtig in Krisenfällen. Ich möchte hier nur zwei Beispiele nennen.

Kurz nach dem Krieg durften die Bürgermeister Wohnungen beschlagnahmen wegen des Wohnungsmangels. Ich möchte auch einen etwas neueren Fall erwähnen; er ist in Nantes geschehen. Die Fischer aus der Bretagne wollten, daß eine Konservenfabrik keine Konserven mit Fischen aus Marokko herstellt. Die Fabrik hat trotzdem Fische aus Marokko gekauft, und das Schiff sollte bald landen und entladen werden. Der Präfekt beschloß darauf wegen der Unruhen einfach, daß die Entladung nicht stattfinden sollte.

Dann erhob die Fabrik eine Klage auf Schadenersatz. Der Conseil d'Etat stellte die Rechtmäßigkeit der Entscheidung des 
Präfekten fest und erkannte nur einen Schadenersatz aufgrund eines enteignungsgleichen Eingriffs an.

Dies nur, um zu zeigen, daß insbesondere in Krisenfällen die allgemeinen Polizeibefugnisse eine besondere Bedeutung erlangen. Ist es in solchen Fällen möglich - deshalb möchte ich Herrn Knemeyer die folgende Frage stellen -, das Opportunitätsprinzip einfach abzuschaffen? In Frankreich wird in einem solchen Fall das Ermessen grundsätzlich anerkannt, aber seine Ausübung wird durch das Gericht zwar flexibel, aber doch grundsätzlich eingehend nachgeprüft.

Vogel: So ungern ich dem von mir so verehrten Herrn Kollegen Scheuner widerspreche - es ist, ich versichere es ehrenwörtlich, das erste Mal, seit ich dieser Vereinigung angehöre -, so möchte ich doch dem allgemeinen Polizeirecht einen Totenschein nicht ausstellen. Wie sprudelnd lebendig das Polizeirecht noch ist, ergibt sich, meine ich, allein schon aus der Rechtsprechung der Verwaltungsgerichte bis hin zum Bundesverwaltungsgericht; seit Erscheinen des „Drews“, Band 1, ist es schon wieder ein ganzer Kasten voll. Die Bedeutung des allgemeinen Polizeirechts sehe ich nach wie vor darin, daB es die rechtsstaatlichen (d. h. liberalen) Grundsätze des Verwaltungsrechts auf dem Gebiet der Gefahrenabwehr kodifiziert. Herr Erichsen hat zu Beginn seines Referats zu Recht von der Gefahr gesprochen, daß sich in den Sonderverwaltungen der Gefahrenabwehr spezialisierte Eliten bilden, und er hat auf den Verlust an Rechtsstaatlichkeit hingewiesen, den das mit sich bringen würde. Ein Totenschein für das allgemeine Polizeirecht würde diesen Sonderverwaltungen das Gravitationszentrum nehmen und sie gewissermaßen in die Tiefe des rechtsstaatlosen Weltraums abschwirren lassen. (Ich entschuldige mich für das etwas pathetisch geratene Bild; es ist mir so schnell kein besseres eingefallen.)

Auch die Ausbildung der jungen Juristen im Polizeirecht sehe ich nicht als einen Zopf an. Denn einmal ist das Polizeirecht für eine Einführung in das konkrete Verwaltungsrecht gerade wegen seines überschaubaren Stoffs gut geeignet - wir können doch nicht gleich mit der Flachglas-Entscheidung anfangen! - , und zum anderen ist es geeignet wie kein anderes Gebiet, der jungen Generation, unseren künftigen Juristen, deutlich zu machen, daß Freiheit schutzwürdig ist, daß Freiheit aber zugleich ihre Grenzen hat und daß, durchaus im Sinne von Herrn Herzog, der einzelne auf einen Schutz dieser Freiheit auch einen Anspruch hat. 
Erichsen: Herr Götz, ich stimme weitgehend mit Ihnen überein. Auf Thre Frage, ob sich meine These 8 nur auf die Aufgabenzuweisungsnorm beziehe, darf ich differenziert antworten. Da $\S 14$ OBG in Nordrhein-Westfalen und die entsprechenden Normen in den anderen Ländern eine im einzelnen Falle bestehende Gefahr verlangen, ist der Ansatz, den ich für die Aufgabenzuweisungsnorm entwickelt habe, von vornherein reduziert.

Herr Friauf, mit Ihnen stimme ich in der Diagnose weitgehend, in den Folgerungen, die daraus zu ziehen sind, fast gar nicht überein. Das führt zunächst - ich darf Herrn Vogel und Herrn Martens in die weiteren Äußerungen einbeziehen - zu der Frage nach dem materiellen Polizeibegriff.

Herr Martens hat in seinem Beitrag gesagt, daß dieser materielle Polizeibegriff Ausdruck einer rechtsstaatlichen Staatskonstituierung sei. Als solchen habe ich ihn auch begriffen. Da wir heute nicht mehr nur im Rechtsstaat, sondern im sozialen Rechtsstaat leben, habe ich gemeint, da $\beta$ wir aus diesem Grunde - wie auch aus manchen anderen Gründen - den materiellen Polizeibegriff verabschieden müßten. Ich möchte in der Tat die Auffassung vertreten - Herr Vogel, ich darf mit Befriedigung feststellen, daß wir gar nicht so weit auseinander liegen -, daß man die Wohlfahrtspflege durchaus in das einbeziehen sollte, was von seiten der Ordnungsverwaltung und Polizei geschehen darf. Ich würde hier vielleicht etwas weiter gehen als Sie, Herr Vogel, doch wenn man Ihr Buch zur Hand nimmt, gewinnt man ja durchaus den Eindruck, daß Polizei in gewisser Weise allem unterlegt ist, was heute in der Verwaltung geschieht.

Sie hatten dann noch die Frage aufgeworfen, wie es denn mit dem Regelkreis sei. Ich möchte hier nicht über Terminologie streiten und wäre in Ubereinstimmung mit Ihnen auch bereit, "gesellschaftliche Vorstellung" an die Stelle dieses Begriffes zu setzen. Sie haben aber dann Ihre Frage dahingehend fortgesetzt, ob ich denn der Meinung sei, da $B$ auch eine von der Mehrheit im Rahmen der öffentlichen Ordnung entwickelte Auffassung über die Notwendigkeit von Wohlfahrtspflege von der Polizei- oder der Ordnungsbehörde umgesetzt werden müßte. Dieser Auffassung bin ich deshalb nicht, weil das Subsidiaritätsprinzip von vornherein diese Möglichkeiten sperrt. Etwas wie eine Mindestlohngarantie oder was es sonst sein mag, fällt schon deshalb nicht in den Zuständigkeitsbereich von Ordnungsverwaltung und Polizei. 
Herr Häberle, ich habe versucht, Ihrer Sorge um die Verfassungsbezüglichkeit des Polizeirechts in meinem Referat Rechnung zu tragen. Die Probleme der pluralistischen Demokratie sind möglicherweise etwas zu kurz gekommen. Ich würde den Problemansatz etwa im Gegensatz zu dem, was Herr Denninger früher einmal publiziert hat, nicht in den mit dem Schutzgut der öffentlichen Ordnung verbundenen Fragestellungen, sondern in der öffentlichen Sicherheit verorten. Unter Bezug auf das, was ich im Referat gesagt habe, darf ich darauf hinweisen, $\mathrm{da} B$ ich es ausdrücklich zu den Aufgaben von Ordnungsverwaltung und Polizei gerechnet habe, die Funktionsfähigkeit der Verfahren, und zwar auch jener Verfahren zu gewährleisten, die im gesellschaftlichen Bereich entstehende neue Auffassungen im staatlichen Bereich zur Wirkung bringen sollen.

Noch ein paar abschließende Worte zur öffentlichen Ordnung. Die öffentliche Ordnung ist in gewisser Weise ein besonderes Opfer der Verlustliste geworden, die man als Referent gewissermaßen immer mit vorzulegen hat. Die öffentliche Ordnung - Herr Ipsen, ich hatte erwartet, Sie würden rügen, daß ich das Europarecht ganz vergessen hätte - spielt ja im internationalen Bereich und neuerdings auch im europarechtlichen Bereich eine große Rolle. Dieser Hintergrund, den ich in meinem Referat einfach aus Zeitgründen nicht habe ansprechen können, hat für mich bei dem Versuch, die öffentliche Ordnung im nationalen deutschen Recht weiterhin fungibel zu erhalten, eine ganz entscheidende Rolle gespielt. Ich glaube, daß es nicht sehr sinnvoll ist, diese Formel für den innerstaatlichen Bereich abzuschaffen, um sie dann alsbald auf dem Wege der Umsetzung internationalen Rechts wiedereingeführt zu bekommen.

Knemeyer: Herr Häberle, Sie haben mich gefragt, ob ich nicht in der Normativierung des Ermessensspielraums ein wenig zu weit gegangen sei. Im Polizeirecht gibt es klare Handlungsaufträge des Gesetzgebers an die Verwaltung, und zwar in den Aufgabenzuweisungsnormen, und auch deutliche Mittelbestimmungsgrundsätze der Geeignetheit und des Ubermaßverbots. Von daher glaube ich nicht, zu weit gegangen zu sein. Ich möchte es nur nicht Normativierung des Ermessensspielraums nennen, sondern Auffüllung dieses vielleicht noch als Merkbegriff verwandten Begriffs des Ermessens. Die Folgen, die man darin vielleicht vermuten möchte, bringt meine Konstruktion nicht - man will ja mit dem Opportunitätsprinzip und dem Ermessen flexibles Handeln der Polizei im Bereich der Gefahrenabwehr ermöglichen -, denn dieses flexible Handeln 
ist über den Gefahrenbegriff einerseits und die Geeignetheit der Mittelbestimmung andererseits gewährleistet.

Herr Scheuner, Sie haben hervorgehoben, wir hätten heute einem stillen Begräbnis beigewohnt. Dieses stille Begräbnis kann aber wohl nur das Polizeirecht im umfassenden Sinne oder den materiellen Polizeibegriff betroffen haben. Ich glaube, ich habe rechtzeitig, wie Herr Badura heute morgen erklärt hat, diesen Atomkern in das Polizeirecht und das Sicherheitsrecht gespalten. Dieses Begräbnis polizeirechtlichen Gedankenguts würde ich für das Sicherheitsrecht akzeptieren, vor allem durch seine Auszehrung und das neue Leben, das das Sicherheitsrecht in den Spezialgesetzen gewinnt. Für das Polizeirecht (als solches) im funktionellen Sinne, wie wir es verstehen, sehe ich ein Begräbnis nicht. Ubrigens macht dieses Begräbnis die Sicht sehr klar für die notwendige Trennung von Polizei- und Sicherheitsrecht.

Herr Fromont, Sie haben für eine starke Polizeigewalt in Krisenfällen plädiert und haben gefragt, ob man eigentlich in Krisenfällen wohl noch wirklich schlagkräftig agieren könne, wenn man auf das Opportunitätsprinzip verzichte. Ich sehe keinerlei Grund, meinem Ansatz zu einem System eine besondere Nuance für Krisenfälle einzufügen. Ich glaube, gerade durch die Aufgabenfeststellung aus den Aufgabenzuweisungsnormen, dann aber vor allem durch die Mittelbestimmung, die ja ex situatione und ex ante zu erfolgen hat, bleibt absolut die Möglichkeit, auch in Krisenfällen wirklich schlagkräftig durchzugreifen.

Als letztes zu Herrn Herzog, der leider gegangen ist. Ich begrüße es sehr, daß Herr Herzog die Bedeutung der Aufgabenzuweisungsnorm in der Sicht, die ich ihr gegeben habe, so sehr unterstrichen hat. Auch stimme ich ihm zu, daß die freiheitssichernde Tendenz des Polizeirechts herausgestellt werden muß. Wir können dies tun, indem wir eben den Begriff der öffentlichen Sicherheit - auch darauf hat Herr Herzog hingewiesen - in die einzelnen Bereiche aufspalten, zum Beispiel Freiheit. Dann hat er einen flammenden Protest angeschlossen. Mir steht es fern, Herrn Kelsen die wohlverdiente Ruhe zu rauben. Ich glaube auch nicht, daß er sich so sehr im Grabe herumdrehen wird, wenn ich seine Grundnorm heute in meinem Referat des öfteren verwandt habe, aber in einem Zusammenhang, wie sie aus dem Baurecht bekannt ist. Dort wird bekanntermaßen der $\S 3$ als die baurechtliche Grundnorm verstanden. Diesen Begriff der Grundnorm des besonderen Verwaltungsrechts, wenn ich es den Osterreichern so sagen darf, habe ich verallgemeinert. 
Vorsitzender: Wir bewegen uns in lauter makabren Vergleichen: „Begräbnis“, „Sargnägel“ und ähnlichem. Ich darf einen posthumen Diskussionsbeitrag, der gedruckt vorliegt, als Intermezzo einschieben:

„Wir haben aus den Referaten von heute vormittag sowohl wie aus den Diskussionen etwas entnehmen können, was auch früher schon bekannt war, nämlich, daß der Polizeibegriff für die Theorie des Verwaltungsrechts herzlich wenig brauchbar ist. Zwar ist er in der Praxis unentbehrlich, aber theoretisch hat er keine besondere Bedeutung. Ich möchte in diesem $\mathrm{Zu}-$ sammenhang einen Namen nennen, das ist der Name Otto Mayer. Er hat in seinem grundsätzlichen Werk einmal sehr richtig gesagt, daß für die Theorie der Polizeibegriff keine Bedeutung habe, aber er möge ruhig weiterlaufen, weil er einmal in der Praxis nicht entbehrt werden könne. Unsere Verhandlungen haben gezeigt, daß sich das auch in der Gegenwart nicht geändert hat."

So Willibalt Apelt - München, auf der Münchener Staatsrechtslehrertagung 1950, als Beitrag zur Aussprache über das Thema „Die Gestaltung des Polizei- und Ordnungsrechts in den Besatzungszonen Deutschlands". Apelt mag die Referenten gegen den Vorwurf juristischer Bilderstürmerei in Schutz nehmen.

Nun aber zum zweiten Problemkreis: „Handlungsbefugnisse und Handlungspflichten der Polizei und Ordnungsverwaltung“.

Lerche: Ich darf anknüpfen an das Stichwort von Herrn Knemeyer über die Auffüllung des Ermessens, das er in Antwort auf die Bemerkung von Herrn Fromont gesagt hat und das er durch den Gedanken der Normativierung des Ermessens ersetzen wollte. Ich darf hinweisen auf die These 5, wo unter Betonung der Bedeutung der Aufgabenzuweisungen gesagt wird, wenn das ganze Schwergewicht darauf liege, so bleibe für ein sogenanntes Entschließungsermessen kein Raum. Dahinter steht wohl die auch sonst nicht unproblematische allgemeinere Vorstellung, je konkreter und je zahlreicher die normativen Aufgabenzuweisungen würden, desto mehr schmelze das Ermessen dahin.

Ich bin mir nicht sicher, ob dieses vielfach gebrauchte Bild wirklich so stimmt. Ist es nicht vielmehr so, daß gerade im Falle einer Kumulierung solcher konkreter Aufgabenzuweisungen auch die Gefahr der Kollisionen der so fixierten Aufgabenzuweisungen anwächst, so daß hier erst recht ein neuartiger Spielraum der Exekutive entsteht, dem ja auch Herr Knemeyer in 
anderer Weise, etwa durch den Gedanken der Abwägung oder am Schluß durch den Gedanken größerer Flexibilität, wieder Rechnung tragen muß? Deshalb würde ich meinen, den Akzent doch etwas anders als Herr Knemeyer setzend, daß hier im Grunde durch die Zunahme von normativen - gerade auch konkreten, nicht nur vagen - Aufgabenzuweisungen der eigentliche Handlungsspielraum der Exekutive unter Umständen sogar zunehmen kann.

Auf der anderen Seite wird es daher aber auch wohl wichtiger - darauf hat Herr Knemeyer in anderem Zusammenhang hingewiesen - , die Bedeutung des Verfahrensinstrumentariums hervorzuheben, denn gerade in dem dadurch garantierten geordneten Verfahren können solche zusätzlichen Spielräume der Verwaltung wieder einigermaßen kanalisiert werden. Insofern also wieder Zustimmung zu Ihrer These.

Bachof: Zum selben Punkt wie Herr Lerche. Aber mein Widerspruch gegen die Verabschiedung des Entschließungsermessens ist noch viel entschiedener. Das gilt insbesondere für den, wie ich meine, untauglichen Versuch, das Ermessen durch rechtlich handhabbare und gerichtlich überprüfbare Bestimmungsmaßstäbe wie Geeignetheit und Ubermaßverbot aufzufüllen. Heute morgen hat Herr Knemeyer dabei besonders auf den Grundsatz der Verhältnismäßigkeit abgestellt. Da möchte ich einhaken, denn ich meine, Verhältnismäßigkeit und Zweckmäßigkeit (Ermessen, Opportunität) sind zwei völlig verschiedene Dinge.

Ich möchte das an einem Beispiel aus jüngster Zeit illustrieren. In der letzten Woche hat es in Tübingen nach Jahren der Ruhe zum ersten Mal wieder schwere Zusammenstöße zwischen Polizei und Studenten gegeben. Der Anlaß war ziemlich unbedeutend: ein vielleicht ungeschicktes Verhalten der Universitätsverwaltung in Fragen der Ersatzgelder und der Koppelung der Rückmeldebescheinigung mit dem Nachweis der Bezahlung dieser Gelder. Es kam zu einer Demonstration mit einem sogenannten Sitzstreik auf einer verkehrsreichen Brücke; der zu dieser Zeit starke Berufsverkehr wurde völlig lahmgelegt. Die Polizei ging mit Helm, Schild und Schlagstock gegen die Sitzenden vor und räumte die Brücke; es gab etliche Verletzte. Die Folge war eine starke Emotionalisierung und Solidarisierung weiter Kreise der Studentenschaft und der Bevölkerung. Den radikalen Urhebern des Ereignisses konnte kein größerer Gefallen getan werden als dies! Endlich nach Jahren haben sie wieder ein Thema, haben sie Stichworte und Schlagworte, mit deren Hilfe sie Rabatz machen können. 
Das Verhalten der Polizei war meines Erachtens rechtmäßig. Es war aber im äußersten Maße unzweckmäßig und unklug. Die Sache hätte sich mit Sicherheit in relativ kurzer Zeit selbst erledigt, da die Passanten gegen die Demonstranten Stellung nahmen. Denn so dumm, die Reaktionen der Bevölkerung zu ignorieren, sind die Demonstranten nicht.

War das unzweckmäßige Verhalten der Polizei aber wegen dieser Unzweckmäßigkeit etwa auch unverhältnismäßig? Das Gebot der Verhältnismäßigkeit bedeutet, daß ein Mittel, das an sich geeignet und erforderlich ist, trotzdem nicht angewandt werden darf, wenn es der Zweck-Mittel-Relation widerspricht. Hier war aber das Vorgehen der Polizei das einzige geeignete und daher auch erforderliche Mittel, um die immerhin recht erhebliche Störung von Recht und Ordnung alsbald zu beseitigen. Also durfte die Polizei einschreiten, auch wenn das Einschreiten nicht opportun war.

Würde man anders argumentieren, würde man also die Auswirkung des polizeilichen Vorgehens auf die Stimmung der Bevölkerung und der Studentenschaft in die Beurteilung der Verhältnismäßigkeit einbeziehen, so hieße das Kapitulation vor dem Terror der Straße. Dann brauchten Randalierer nur mit einer noch weiteren Eskalation als Folge des Einschreitens der Polizei zu drohen, um das Einschreiten der Polizei unverhältnismäßig und damit rechtswidrig erscheinen zu lassen.

Ich meine also, daß Ermessen (Opportunität) und Verhältnismäßigkeit zwei völlig verschiedene Dinge sind. Erinnern wir uns doch nur an die Zeit der Studentenunruhen, als wir als Rektoren, Dekane oder auch nur als Lehrveranstaltungsleiter immer wieder vor die Frage gestellt wurden, ob wir gegen Hörsaalbesetzungen, gegen sogenannte „Streiks“, gegen Dekanatsbesetzungen usw. einschreiten sollten, ob wir solche Aktionen übersehen, ob wir sie sich totlaufen lassen sollten, ob wir arbeitswillige Studenten zum Selbstschutz organisieren sollten, ob wir die Polizei holen sollten usw. Das alles waren keine Fragen der Verhältnismäßigkeit und damit der Rechtmäßigkeit. Wir haben uns in der Regel gar keine Überlegungen über die Rechtmäßigkeit unseres Verhaltens gemacht - nicht etwa, weil wir nicht auf Rechtmäßigkeit bedacht gewesen wären, sondern weil es uns selbstverständlich war, daß wir einschreiten durften. Für uns stellte sich aber die Frage, ob es zweckmäßig sei, einzuschreiten oder nicht. Das war eine reine Frage des Ermessens und nicht der Verhältnismäßigkeit. Wäre es anders, so hätten wir keine Entscheidungsfreiheit gehabt; im konkreten Fall hätten wir stets nur auf eine Weise rechtmäßig 
handeln können: wir hätten entweder einschreiten müssen, oder nicht einschreiten dürfen. Das zeigt, daß es nicht angeht, das Ermessen durch den Begriff der Verhältnismäßigkeit auffangen $\mathrm{zu}$ wollen.

von Mutius: Ich habe zwei Fragen an Herrn Knemeyer, die sich allerdings durch die letzten Diskussionsbeträge von Herrn Fromont, Herrn Lerche und Herrn Bachof teilweise erledigt haben und die ich deshalb gleich etwas konkretisieren möchte.

1. Herr Knemeyer, Sie haben in den Thesen 5 und 7 das Ende des Entschließungsermessens mit dem Hinweis eingeläutet, die Aufgabenzuweisungsnorm verpflichte zur Gefahrenabwehr und nicht dazu, jeder Gefährdung nachzugehen und zu prüfen, ob einzuschreiten sei. Andererseits sagen Sie in These 10, daß die Bearbeitung von Bagatellfällen ergeben könne, daß trotz Vorliegens einer Gefahr nicht eingeschritten werde.

Zunächst zeigt der Vergleich der beiden Thesen $\mathrm{m}$. E., daß in der Tat die Unterscheidung zwischen Entschließungsermessen und Auswahlermessen im Einzelfall problematisch ist, weil die Beurteilung des jeweils in Betracht kommenden Mittels Rückwirkungen darauf haben kann, ob die Behörde überhaupt tätig wird. Insofern würde ich Ihnen zustimmen. Einverstanden wäre ich auch mit einer Interpretation der Aufgabenzuweisungsnorm in dem Sinne, daß das Entschließungsermessen nicht dahingehend mißverstanden werden darf, die Behörde dürfe sich unter Hinweis hierauf der Aufgabe der Gefahrenabwehr völlig entledigen. Aber zeigen nicht gerade die von Ihnen angesprochenen Bagatellfälle, daß es nach wie vor Fallgestaltungen gibt, in denen trotz Vorliegens einer Gefahr für die öffentliche Sicherheit und/oder Ordnung nicht eingeschritten werden muß, so daß es hier zumindest im Ergebnis eben doch auf eine Ausübung des Entschließungsermessens hinausläuft?

Dazu ein weiterer Gesichtspunkt: Wie ordnen Sie in Ihr System die Fälle ein, in denen zwar eine Gefahr für die öffentliche Sicherheit und/oder Ordnung vorliegt, in denen aber im gesellschaftlich-privaten Bereich nach Beurteilung der Polizeiund Ordnungsbehörden hinreichende Mechanismen vorhanden sind, die Gefahr abzuwehren? Ich verweise etwa auf Fälle, in denen die Gefahr von Kindern ausgeht oder Kindern droht und nun die Behörde bei pflichtgemäßer Beurteilung der Lage zu der Auffassung kommen könnte, daß die Ausübung des Erziehungsrechts der Eltern etwa ausreicht, die Gefahr einzudämmen, und deshalb untätig bleibt. Was wäre dies im Sinne Ihrer 
Differenzierung? Ist das eine Anwendung des thermaßverbots? Ist das eine Ausübung des Entschließungsermessens? Oder ist das vielleicht sogar Ausfluß des Subsidiaritätsprinzips, allerdings anders interpretiert als in den Erläuterungen, die uns Herr Erichsen heute morgen zu diesem Terminus gegeben hat?

2. Dann eine zweite Frage: Herr Knemeyer, Sie haben in der These 12 die Verpflichtung der Polizei- und Ordnungsbehörden zum Individualschutz und damit letztlich den Anspruch auf polizeiliches bzw. ordnungsbehördliches Handeln im wesentlichen daraus hergeleitet, daß die polizeiliche Aufgabenzuweisungsnorm Individual- und Kollektivschutzgüter gleichrangig nebeneinanderstelle. Sie haben insoweit, wenn ich das recht in Erinnerung habe, auch auf den Wortlaut der betr. landesrechtlichen Normen hingewiesen. Ich sehe hier einen Gegensatz zum Referat von Herrn Erichsen und darf Sie deshalb fragen: Wenn schon dem Wortlaut maßgebliche Bedeutung zukommt, wie stellen Sie sich dazu, daß der Gesetzestext immer von öffentlicher Sicherheit und von öffentlicher Ordnung spricht und man daraus doch den Schluß ziehen könnte, daß der jeweilige Bezug des geschützten Individualgutes zur Offentlichkeit gegeben sein muß? Also lautet meine Frage: Besteht wirklich ein gleichrangiges Nebeneinander dieser Schutzgüter oder handelt es sich nicht um ein - man könnte sagen - „Miteinander", eine Art Kumulation der Rechtsgüter?

Ergänzend dazu erlauben Sie mir bitte eine letzte Bemerkung, die sich auf Ihre baurechtlichen Ausführungen bezieht. Sie haben hinsichtlich des Bauwichs zu meiner großen Uberraschung behauptet, er bezwecke ausschließlich den Schutz des Nachbarn. Hier würde ich hingegen sagen, da $B$ z. B. die planungsrechtlichen und die feuerschutzpolizeilichen Funktionen des Bauwichs darauf hindeuten, daß dieser zumindestens auch dem Schutz der Allgemeinheit zu dienen bestimmt ist.

Haller: Ich möchte im Zusammenhang mit der Ermächtigungsgrundlage polizeilichen Handelns eine kleine rechtsvergleichende Betrachtung über die Regelung des Schußwaffengebrauchs in der Bundesrepublik Deutschland und in der Schweiz einflechten. Es zeigt sich nämlich, daß das, was Herr Kollege Funk als Gesetzgebungsdefizit bezeichnet hat, in der Schweiz besonders groß ist, wenn es um die gesetzliche Regelung des unmittelbaren Zwanges durch die Polizei geht. Während die deutschen Ländergesetze einläßliche Bestimmungen über das polizeiliche Instrumentarium enthalten, finden wir in den schweizerischen Polizeigesetzen praktisch nur dienst- und 
disziplinarrechtliche Vorschriften. Zwar hat jeder Kanton eine Strafprozeßordnung. Wo es aber nicht um die Verbrechensbekämpfung, sondern um allgemeine polizeiliche Aufgaben geht, werden wichtigste Eingriffe in die persönliche Freiheit bloß auf Verordnungsstufe geregelt, teilweise sogar in Erlassen, die als Dienstverordnungen zu klassifizieren sind. So findet man beispielsweise die Bestimmungen über den Schußwaffengebrauch in einem kantonalen Dienstreglement neben Vorschriften über das Verbot des Tanzens von Polizisten in Wirtschaften.

Der deutsche Musterentwurf verankert nicht nur den Grundsatz der Verhältnismäßigkeit, sondern konkretisiert ihn bezüglich des Schußwaffengebrauchs in $\S \S 41 \mathrm{ff}$. und schränkt damit das polizeiliche Auswahlermessen erheblich ein.

In der Schweiz finden wir nur in drei kantonalen Gesetzen materielle Regelungen über den Schußwaffengebrauch. Es ergibt sich eine Kollision zwischen dem rechtsstaatlichen Postulat nach einer gesetzmäßigen Verankerung und dem Erfordernis nach einer einheitlichen Regelung wichtiger Einschränkungen persönlicher Rechte. Eine Kommission hat in der Schweiz einheitliche Bestimmungen über den Schußwaffengebrauch ausgearbeitet. Wie kann man aber dafür sorgen, daß diese Bestimmungen geltendes Recht werden? Ich weiß nicht, wie optimistisch Sie die Möglichkeiten in Deutschland beurteilen, daß der Musterentwurf in die Ländergesetze übergeführt wird. In der Schweiz haben wir dadurch eine zusätzliche Komplikation, daß wir das Gesetzesreferendum kennen. Ich glaube nicht, daß wir irgendwelche Bestimmungen über Waffengebrauch gegen eine Menschenmenge oder über den Einsatz von Sprengmitteln durch eine Volksabstimmung bringen könnten. Deshalb diese Flucht in die Verordnungen.

Mußgnug: Ich möchte dem, was Herr Bachof gesagt hat, eine Ergänzung hinzufügen und mich der Kritik anschließen, die er an Herrn Knemeyers Versuch, das Opportunitätsprinzip abzuschaffen, geübt hat. Dazu veranlaßt mich ein den Tübinger Vorfällen ähnlicher, aber genau umgekehrt verlaufener Fall aus der akademischen Radauszene, der sich in Berlin ereignet hat. Dort haben die von Herrn Herzog apostrophierten randalierenden Wanderdemokraten im Sommer 1972 über dem Portal der Technischen Hochschule ein garstiges Transparent angebracht. Der Innensenator hat den Präsidenten der TU angewiesen, seine Universität sofort wieder von diesem sonderbaren Schmuck zu reinigen. Das aber hat der Präsident entschieden abgelehnt. Darauf hat ihm der Innensenator mitge- 
teilt, er werde die Polizei schicken, wenn das Transparent nicht sofort beseitigt werde. Auch das hat der Präsident der TU nicht auf sich sitzenlassen, sondern das Verwaltungsgericht angerufen. Dieses hat den Polizeieinsatz in einer seiner schwächsten Stunden im Wege der einstweiligen Anordnung verboten. Zur Begründung hat es auf anderthalb Schreibmaschinenseiten ausgeführt, ihm liege eine eidesstattliche Versicherung der Pressereferentin des TU-Präsidenten vor, die befürchte, daß höchstwahrscheinlich eine Streitmacht von mehreren hundert Rabauken aus der FU zur Verteidigung des Transparents anrücken werde, wenn die Polizei es wagen sollte, daran Hand anzulegen. Angesichts dieses wahrhaft königlichen Beweismittels hielt es das Verwaltungsgericht für absolut unverhältnismäßig, gegen das Transparent einzuschreiten').

Damit hat das Verwaltungsgericht Berlin das VerhältnismäBigkeitsprinzip auf das Gröbste verballhornt. Seine Rechtsauffassung läuft darauf hinaus, den strafbaren Widerstand gegen die Staatsgewalt zum Vollstreckungshindernis aufzuforsten. Ich verzichte darauf, die Konsequenzen auszumalen, die diese Irrlehre auslösen würde, wenn man sie in das Zwangsvollstreckungsrecht der ZPO übertragen würde. Ihre Folgen sind schon dann verhängnisvoll genug, wenn sie nur das Polizeirecht aus den Angeln heben. Hätte das Berliner Verwaltungsgericht nämlich recht, so würde das bedeuten, daß bei der befürchteten Prügelei zwischen der Polizei und den Verteidigern des ominösen Transparents die Polizei unverhältnismäßig und damit rechtswidrig, die Verteidiger indessen verhältnisund damit auch rechtmäßig gehandelt hätten. Die Polizisten wären wegen Körperverletzung im Amt zu verurteilen gewesen. Das gegen sie ins Feld geschickte Rollkommando dagegen hätte vom Vorwurf des Widerstands gegen die Staatsgewalt freigesprochen werden müssen, weil die sonderbare Handhabung des Verhältnismäßigkeitsprinzips durch das Verwaltungsgericht Berlin ihrer Gewalttätigkeit die Zauberkraft verleiht, sich aus sich selbst heraus zu rechtfertigen.

Angesichts dieser abstrusen Folgen bleibt gar nichts anderes übrig, als mit Herrn Bachof nachhaltig für die Beibehaltung des Opportunitätsprinzips zu streiten. Die Form, in der es das Berliner Verwaltungsgericht vom Tisch gefegt hat, ist PopJurisprudenz, die auf Berlin beschränkt bleiben sollte.

Aber damit nicht genug. Die Abschaffung des Opportunitätsprinzips und seine Ersetzung durch das Verhältnismäßigkeits-

1) Der Beschluß trägt das Datum vom 7. 7. 1972 und das Aktenzeichen VG I A 244.72 . 
prinzip würde auch die Spielregeln der parlamentarischen Demokratie aushöhlen. Denn ein Senator oder Minister, dem die Verwaltungsgerichte durch einstweilige Anordnung befehlen, wie er sein Entschließungsermessen auszuüben hat, ist damit aus seiner parlamentarischen Verantwortung entlassen. Er kann bei entsprechenden parlamentarischen Anfragen vor das Parlament treten und erklären, er habe sich redlich bemüht, die Sicherheit und Ordnung aufrechtzuerhalten. Aber das zuständige Verwaltungsgericht habe ihn durch einstweilige Anordnung daran gehindert zu tun, was er für richtig gehalten habe. Damit ist der parlamentarischen Verantwortlichkeit der Regierung für die Ausübung ihrer Polizeiaufgaben der Boden entzogen. Denn sie kann nicht verantworten, was nach Tilgung des Opportunitätsprinzips in die Kompetenz unabhängiger Richter fallen wird, die anders als Senatoren und Minister auch dann nicht zur Rechenschaft gezogen werden können, wenn sie unter der Flagge der Rechtsauslegung Entscheidungen treffen, die nur politisch gefällt werden können, dafür aber auch politisch verantwortet werden müssen. Vor allem die politische Verantwortung der Regierung und ihre Kontrolle durch das Parlament gebieten es daher zwingend, am Opportunitätsprinzip unbeirrt festzuhalten.

Grabitz: Ich wurde motiviert, das Wort kurz zu ergreifen, aus einer Not, die jemand hat, der mit einer praktizierenden Staatsanwältin verehelicht ist und ihr während des Mittagessens auf die Frage, was wir gemacht hätten, erzählt, wir hätten das Opportunitätsprinzip begraben. Daraufhin hat sie Worte gebraucht, die ich selbstverständlich in dieser Aula nicht wiedergeben kann, sondern die dem Schutz der Privatsphäre unterliegen und die sicherlich zur Charakterisierung dieser Versammlung auch nicht treffend sind. Das möchte ich ausdrücklich betonen.

Aber Spaß beiseite! Herr Mußgnug hat es schon angedeutet. Auch ich meine, man darf Polizeirecht nicht ausschließlich als geronnenes Verfassungsrecht ansehen, sondern muß auch betrachten, daß die Verfassung noch andere Komponenten hat als nur Grundrechte und als das nicht einmal darin geschriebene Verhältnismäßigkeitsprinzip.

Ich glaube, die Stellung der Polizei - man muß hier die Frage stellen: Wer ist denn eigentlich die Polizei; das ist ja kein Abstraktum - innerhalb der Verfassungsordnung, besser: innerhalb der staatlichen Ordnung hat, glaube ich, bestimmte Konsequenzen auch auf die Formulierung der Weite 
und der Qualität ihrer Eingriffsnormen, also für die Frage, ob sie einen Raum für Zweckmäßigkeitserwägungen lassen oder alles reduzieren auf eine reine Rechtsanwendung.

Ich bezweifle - das will ich vorwegschicken - ob das, was Sie vorschlagen, Herr Knemeyer, praktikabel ist. In Ihrer These 7 heißt es: „Die Aufgabennorm verpflichtet zur Gefahrenabwehr und nicht dazu, jeder Gefährdung nachzugehen und zu prüfen, ob einzuschreiten ist". Welcher Gefährdung darf sie denn nicht nachgehen? Das ist das Problem, das Sie offensichtlich nicht lösen können. Dann soll man aber offen sagen: Es gibt einen Bereich, wo reine Zweckmäßigkeits- und taktische Uberlegungen eine Rolle spielen.

Herr Mußgnug hat auf das Problem der parlamentarischen Verantwortlichkeit, der parlamentarischen Kontrolle des Ministers hingewiesen. Polizei ist eben nicht nur eine Institution, sondern verkörpert sich durch eine politisch handelnde Figur, und das ist in aller Regel der Innenminister, der damit auch ein Stück praktischer Politik nachher vor der Instanz zu verantworten hat, die ihn gewählt und die ihn zu kontrollieren hat.

Ich will aber noch ein Stück weitergehen: Handeln tun ja doch Beamte innerhalb der Polizeiorganisation. Nun muß man sich einmal überlegen: Wenn auch dieses Handeln - man muß es ja so formulieren - nur noch auf die von Herrn Bachof völlig richtig herausgestellte Entscheidung „rechtswidrig oder rechtmäßig" reduziert wird - -

\section{(Zuruf Bachof)}

- Ja, sie müssen das aber auch lesen können. Das ist das Schwierige. Nicht jeder Polizist ist darin ausgebildet. Ich meine, er muß auch die Kommentare dazu lesen können. Das ist doch viel wichtiger als das, was im Text steht.

Hören Sie sich einmal in der Polizeiorganisation um. Die Entscheidungsfreudigkeit der Vollzugspolizei schwindet in dem Maße, als ein Minister - das ist im übrigen allgemeine Tendenz - nicht mehr die Verantwortung übernimmt. Wenn man Ihnen folgt, Herr Knemeyer, dann darf er es im Grunde ja gar nicht, sondern dann ist der, der kontrolliert, der Verwaltungsrichter. Der Minister hat dann überhaupt keinen Anlaß, sich irgendwann vor einen Beamten zu stellen, der meinetwegen eine unzweckmäßige Entscheidung getroffen hat, was möglich ist und eigentlich von der parlamentarischen Verantwortungsordnung auch vorausgesetzt wird. 
Bullinger: Ihr Leitsatz 28, Herr Knemeyer, erweckt zunächst den Anschein, als verbliebe auch bei Threr Theorie der Polizei noch eine gewisse Flexibilität. Wörtlich heißt es: „Die Fülle unbestimmter Begriffe ... beläßt der Verwaltung eine Bandbreite der Entscheidung". Das würde ich als Ermessen oder Beurteilungsspielraum verstehen. Diese Freiheit der Entscheidung aber, so lautet der letzte Satzteil, pflanze sich schließlich auf die Verwaltungsrechtsprechung fort. Sie meinen wahrscheinlich - das wäre aber das Gegenteil dessen, was Sie zunächst sagen wollen - , daß die Verwaltungsrechtsprechung doch eine volle richterliche Nachprüfung als ihre Aufgabe ansehen dürfe. Dann fehlte eben der Verwaltung doch wieder die Flexibilität.

Mir scheint innerhalb dieses Leitsatzes eine gewisse Spannweite möglicher Interpretation $\mathrm{zu}$ bestehen.

Blümel: Erlauben Sie mir einige Bemerkungen zu einem anderen Aspekt, und zwar zu den Thesen $16 \mathrm{ff}$. und $22 \mathrm{ff}$. des Referats von Herrn Kollegen Knemeyer.

Herr Knemeyer, in These 19 sagen Sie: „Wann aber ein Gebot dem Interesse des einzelnen dient, ergibt die die Anlagennormen bestimmende Grundnorm". Für das Baurecht sehen Sie diese Grundnorm in $\S 3$ der Musterbauordnung. Dieses System, das Sie hier für das Baurecht entwickelt haben, übertragen Sie zum Beispiel auf das andersartige Atomrecht, ohne jedoch zu sagen, in welcher Vorschrift des Atomgesetzes etwa Sie die Grundnorm erblicken. Dieser Verzicht kommt aber wohl nicht ganz von ungefähr, denn nach meiner Auffassung kann man die Threm System zugrunde liegende Unterscheidung von Anlagennormen und bestimmender Grundnorm nicht durchhalten. Abgesehen davon, daß es Gesetze gibt, die keine Grundnorm kennen, wird man auch in den übrigen Gesetzen, etwa im Atomgesetz, das ja vor den nuklear-spezifischen Gefahren sichern soll (\$1), den Schutzanspruch des einzelnen in vielen Fällen und in verschiedener Hinsicht unmittelbar aus den Anlagennormen selbst entnehmen müssen. Für das Atomgesetz wäre das die Vorschrift des $\S 7$ über die atomrechtliche Genehmigung. Daraus folgt aber, daß man die einschlägige Gesetzgebung nicht in das von Ihnen entwickelte System pressen kann. In diesem Punkt folge ich auch den Ausführungen von Herrn Martens.

Zweitens: Ihre Ausführungen zu den Thesen 25 und 26, also Ihre Auslegung der Präklusionsvorschriften, halte ich für unzutreffend. Abgesehen davon, daß Sie nicht hinreichend genug 
differenzieren - für das Bundesfernstraßengesetz etwa gilt etwas anderes als für das Wasserrecht und für das Atomrecht -, steht Ihr Ergebnis mit der Praxis und mit der Rechtsprechung nicht in Einklang.

Die von Ihnen zitierte Entscheidung des OVG Lüneburg ist, soweit ich sehe, vereinzelt geblieben. Ich verweise demgegenüber auf die das Kernkraftwerk Wyhl betreffenden Urteile des Verwaitungsgerichts Freiburg vom 8. April 1976'), in denen das Gericht mit ausführlicher, Schrifttum und Rechtsprechung zusammenfassender Begründung zur Bedeutung der atomrechtlichen Präklusionsfrist Stellung nimmt. In dem Sasbach-Urteil wurde die Klage für zulässig erklärt, obwohl die innerhalb der Frist erhobenen Einwendungen erst nach Ablauf der Frist begründet worden sind. In letzter Hinsicht halte ich das Urteil zwar für erörterungsbedürftig; die grundsätzliche Bejahung der Präklusionsfrist, auch ihre verfassungsrechtliche Zulässigkeit, ist jedoch entgegen dem Ansatz in Ihrem Referat zutreffend.

Ohlinger: Meine Wortmeldung ist angeregt worden durch den Beitrag von Herrn Lerche, den ich unterstreichen und in einer Art Rechtsvergleichung aus österreichischer Sicht illustrieren möchte. Es ist allgemein bekannt, daß wir in Österreich unter besonders strengen Anforderungen des Legalitätsprinzips stehen. Wir haben daher in unserem Recht besonders zahlreiche, enge und spezielle gesetzliche Bindungen und Ermächtigungen der Verwaltung im allgemeinen und der Polizei im besonderen, was ja - Herr Funk hat davon berichtet - in der Lehre dazu führt, den Polizeibegriff überhaupt aufzulösen oder aber auf den engen Bereich der "Sicherheitspolizei" $z u$ reduzieren, der viel weniger erfaßt, als hier unter dem Stichwort "Polizei“ abgehandelt wird. (Ich möchte dem nur hinzufügen, $\mathrm{da} \beta \mathrm{mir}$ die hier vorgetragenen Einwände gegen ein derartiges „Begräbnis“ des Polizeibegriffs für den österreichischen Bereich in der Tat nicht stichhaltig erscheinen und ich die österreichische Reduktion des Polizeibegriffs für richtig halte. Doch will ich damit nicht zur deutschen Rechtslage Stellung nehmen.)

Ich möchte hier von einer Untersuchung berichten, die am Institut für Staats- und Verwaltungsrecht in Wien in Angriff genommen wurde und die sich mit der Frage beschäftigt: Wie setzt sich diese Fülle der gesetzlichen Regelungen faktisch in

1) DVBl. 1976, 804, 807 (809). 
das konkrete Handeln der Polizeiorgane (in dem engen Sinn des auf der Straße patrouillierenden „Polizisten“ etc.) um?

Wir konnten dabei ermitteln, daß zwar diese Polizeiorgane eine theoretische Schulung erfahren, in denen durchaus der Gehalt der gesetzlichen Bestimmungen referiert wird. Die eigentliche "Schulung" erfolgt jedoch ausschließlich in der Praxis, und zwar durch erfahrene Kollegen, denen die Behörde vertraut. Dabei bilden sich handlungsauslösende Programme, die - und das scheint mit entscheidend - weit hinter dem zurückbleiben, wozu die Gesetze tatsächlich ermächtigen würden. Die Polizei nützt nicht annähernd ihren gesetzlichen Handlungsspielraum, sondern zieht ihrer Tätigkeit selbst engere Grenzen, wobei sie sich außer am Gesetz auch und sogar primär an anderen Faktoren orientiert.

An einem banalen Beispiel illustriert: Ein Gesetz schreibt vor, daß Kraftfahrzeuge nicht „unnötigen Rauch und üblen Geruch" erzeugen dürfen. Schon die Terminologie verrät das Alter dieser Regelung: sie ist mehr als fünfzig Jahre alt, soll aber heute die ganze Problematik der Umweltbelastung durch Kraftfahrzeuge gesetzlich einfangen. Dieser Terminus wird nun in der Praxis der Polizei von vornherein nur auf ganz wenige Kraftfahrzeugtypen bezogen. Das Sicherheitswacheorgan wird in seiner Ausbildung darauf trainiert, nur bei bestimmten Fahrzeugen (Lkw, Autobusse usw.) auf übermäßigen „Rauch und üblen Geruch" zu achten. Es gibt nun allerdings in der Verwaltungsrechtsprechung der letzten zwanzig Jahre einen einzigen Fall, in dem auch der Fahrer eines Pkw mit Benzinmotor aufgrund dieser Vorschrift bestraft wurde. Der Sachverhalt, soweit aus der Veröffentlichung der Entscheidung erkennbar, deutet freilich darauf hin, daß dabei für die Polizei auch andere Motive eine Rolle spielten.

An diesem Beispiel wird deutlich, daß eine Verdichtung der gesetzlichen Ermächtigungen, deren vom Legalitätsprinzip her vorgezeichneter Sinn es ist, das polizeiliche Handeln möglichst eng und für jeden nur denkbaren Fall voraus berechenbar zu determinieren, das Gegenteil bewirken kann, weil sozusagen die Quantität in eine andere Qualität umschlägt. Denn in ihrer Fülle lassen sich die gesetzlichen Bestimmungen gar nicht ständig und auch nur annähernd lückenlos in die Realität umsetzen. Die Polizei muß vielmehr eine Auswahl vornehmen, muß "Prioritäten“ setzen. Unterschiedliche Zielsetzungen führen überdies zu Zielkonflikten, die von der Polizei selbständig zu lösen sind und damit ebenfalls ihren Entscheidungsspielraum erweitern - ein Problem, das wir aus dem Raumordnungs- 
recht kennen, das aber offenbar auch in einem so "klassischen" Verwaltungsgebiet wie dem der Polizei besteht. Damit entstehen neue Formen des "Ermessens", die freilich mit den "klassischen" Kategorien und Distinktionen der Ermessenslehre kaum erfaßbar sind und daher auch ganz neue Probleme der Verwaltung aufwerfen.

Breuer: Herr Knemeyer, ich habe zu Punkt 2 unserer Diskussion Bedenken anzumelden gegen ihren grundsätzlichen Ansatz, Schutzansprüche und Schutzpflichten aus den Aufgabenzuweisungs- und Zwecknormen herzuleiten. Dabei stehen wir heute vor einer Vielzahl moderner Gesetze. Ich darf an das Immissionsschutzrecht erinnern, auch an das Wasserrecht, das durch einen neuen $\S 1$ a WHG eine solche Zwecknorm erhalten hat. In allen diesen Gesetzen zeichnen sich die Zwecknormen wie auch die Aufgabenzuweisungsnormen durch eine erhebliche Unbestimmtheit aus. Ist - so möchte ich fragen deswegen nicht zu befürchten, daß hier Schutzansprüche mit korrespondierenden Schutzpflichten der Verwaltung in unübersichtlichem Maße konstruiert werden? Das halte ich deswegen für nicht ganz unbedenklich, weil wir als Hintergrund des gesamten Ordnungsrechts immer eine wechselseitige Grundrechtsbeziehung ins Auge fassen müssen. Es geht nicht nur um Grundrechte und sonstige subjektive Rechte desjenigen, der sich mit Schutzansprüchen gegen die Ordnungsverwaltung wendet, sondern es geht ebenso um die Rechtsposition desjenigen, der seine Freiheit ausüben will und als Störer oder angeblicher Störer in Anspruch genommen werden soll.

Die genannten wie auch ähnliche Gesetze bemühen sich nun, die schlichten Formelkompromisse der Zwecknormen in eine Reihe von Einzelnormen aufzulösen. In diesen Einzelnormen ist wesentlich präziser angegeben, welche Rechtspositionen etwa derjenige geltend machen kann, der sich gegen die Zulassung einer Anlage wehrt. So finden sich z. B. in den Vorschriften des Immissionsschutzrechts und des Wasserrechts über die Zulassung von Vorhaben Ansätze eines differenzierten öffentlichen Nachbarrechts. Ist es daher nicht unvereinbar mit der Systematik dieser Gesetze, wenn Sie an die Zwecknormen anknüpfen und das differenzierte System von Zulassungs-, Einwendungs- und Abwehrrechten übergehen? Diese Frage scheint mehr systematischer Art zu sein, sie hat aber den grundrechtlichen Hintergrund und scheint mir doch von größerer praktischer Bedeutung zu sein. Ich darf daher fragen, wie Sie diese Frage in systematischer und grundrechtlicher Hinsicht auflösen wollen. 
Götz: Die Unterscheidung zwischen dem Entschließungsermessen und dem Auswahlermessen - in dieser Richtung hat Herr von Mutius schon einige Bemerkungen gemacht - ist eigentlich nur eine gedankliche. Sie ist keine reale Unterscheidung der polizeilichen und ordnungsbehördlichen Praxis.

Wir dürfen uns nicht vorstellen, daß Polizei oder Ordnungsbehörde zunächst gewissermaßen in einem Grundurteil entscheiden, ob sie überhaupt einschreiten wollen, und wenn diese Entscheidung bejaht ist, sich der Frage zuwenden, mit welchen Mitteln sie einschreiten.

Es geht doch nach meinem Dafürhalten um die einheitliche Frage, wie die Behörde auf einen bestimmten, ihr vorliegenden Sachverhalt reagiert. Es ist die einheitliche Frage, wie im Sinne der Gefahrenabwehraufgabe tätig zu werden ist. Zu diesem "wie zu handeln ist" gehört dann auch unter Umständen als ein Ergebnis, daß in einem Einzelfall nicht eingeschritten werde.

Insofern haben wir nach wie vor das Ermessen der Verwaltung, und, Herr Knemeyer, ich kann Sie nicht dahin verstehen, daß dieses Ermessen abgeschafft werden sollte. Vielmehr sind Ihre Ausführungen aus meiner Sicht nur so zu verstehen, daß Sie sich gegen ein sozusagen vorgeschaltetes Entschließungsermessen wenden. Wenn das so wäre, würde ich Ihnen ohne weiteres zustimmen, zumal ich Ihre Ausgangsposition, daß die Aufgabennorm zur Gefahrenabwehr verpflichtet, uneingeschränkt teile.

Auch Thre Aussage, daß einzuschreiten ist, wenn der Zweck der Ermächtigung dies erfordert, würde man ohne weiteres teilen können. Wie gesagt: Zweifel stellen sich nur ein, wenn Sie dies in die Formel von der Ausschaltung des Opportunitätsprinzips einkleiden. Ich glaube, daß Sie sicher die Gelegenheit wahrnehmen werden, erläuternde Bemerkungen zu Ihren Thesen im Zusammenhang Ihres anschließenden Schlußwortes zu machen.

Erichsen: Ich möchte nur noch einmal betonen, daß ich hier eine völlig gegensätzliche Position zu Herrn Knemeyer beziehen wollte.

Ich möchte diese gegensätzliche Position auch im Hinblick auf die neue Regelung des $\S 40$ Verwaltungsverfahrensgesetz des Bundes aufrechterhalten, wo im Hinblick auf die Ermessensausübung die Bindung der Verwaltung an den Zweck der Ermächtigung zum ausdrücklichen Gegenstand der gesetzlichen Regelung gemacht worden ist. 
Knemeyer: Herr Bachof, ich hatte Ihren Widerspruch gegen die Verabschiedung des Entschließungsermessens selbstverständlich erwartet. Ich möchte versuchen, es dennoch zu rechtfertigen, und zwar auch auf dem Hintergrund der Fälle, die Sie und Herr Mußgnug hier so plastisch dargelegt haben.

Ich glaube, ich komme auch unter Verabschiedung des Entschließungsermessens - Herr Götz, hier würde ich beides trennen, also Entschließungsermessen und Auswahlermessen, so wie es herkömmlich ist - zu praktikablen Ergebnissen, ohne das Gespenst, das gerade Herr Mußgnug an die Wand gemalt hat, zu sehen.

Wesentlich erscheint mir, daß diese plastischen Beispiele, die Sie gebracht haben, aus einer ex-post-Sicht stammen. Sie stammen aus der Sicht des Richters und nicht aus der Sicht des Verwaltungsbeamten in der Situation. Der Verwaltungsbeamte sieht die Gefahr, und wenn er die Gefahr im Sinne der Aufgabenzuweisungsnorm sieht, dann ergibt sich daraus für ihn die Schutzpflicht.

In einem zweiten gedanklichen Gang - ich möchte, Herr Götz, durchaus dazwischen unterscheiden - legt er fest, mit welchen geeigneten, erforderlichen und verhältnismäßigen Mitteln er zweckentsprechend handeln kann.

Wenn wir uns die Definition des Grundsatzes der Verhältnismäßigkeit im engeren Sinne anschauen - so, wie sie der Musterentwurf gefaßt hat und wie sie auch sicherlich der Unterscheidung, die Herr Lerche herausgearbeitet hat, entspricht -, so würde ich gerade diese StraßenbahnblockadeFälle zum Beispiel in Hannover oder auch den Fall, den Herr Bachof aus der jüngsten Zeit gebracht hat, darüber lösen wollen.

Eine Maßnahme darf nicht zu einem Nachteil führen, der zu dem erstrebten Erfolg erkennbar außer Verhältnis steht; also Verhältnismäßigkeit im engeren Sinne. Hier ist über den Begriff des Nachteils die Möglichkeit und die Notwendigkeit gegeben, in einer Art Prognoseentscheidung durch die Verwaltung im augenblicklichen Zeitpunkt festzustellen, was denn herauskommt, wenn jetzt gehandelt wird.

Herr Bachof, es ist für meine Begriffe sicherlich ein Unterschied zwischen Zweckmäßigkeit und Verhältnismäßigkeit. Sie haben es Aliud genannt und haben gesagt, Sie lösten die Sache über den Begriff der Zweckmäßigkeit; ein Globalbegriff, wie immer man ihn fassen will. Ich würde hier die Frage über den Begriff der Verhältnismäßigkeit lösen wollen und sagen: Im 
Beispiel der Verkehrsblockade hätte es zu einem unverhältnismäßigen Nachteil geführt, wenn die Polizei eingeschritten wäre in Kenntnis der Tatsache, daß sich dann diese Menge, ihren Drohungen entsprechend, in Bewegung gesetzt und Schaufenster zerschlagen hätte usw. und es zu einer weiteren Eskalation gekommen wäre.

Aber das Wesentliche ist: Wir sind als Richter immer klüger als der Polizeibeamte in der Situation. Das darf man nicht miteinander mischen. Aus der Situation muß die Entscheidung folgen. Dann ist in der Tat für meine Begriffe dieser Grundsatz der Verhältnismäßigkeit ein Lösungsweg.

Es gilt dabei sicherlich, die Folgen zu beachten. Herr Bullinger hat auf These 28 hingewiesen, eine These, die im Bereich des Atom- und Immissionsschutzrechts angesiedelt ist. Hier habe ich in der Tat von einer Bandbreite der Entscheidung gesprochen, die der Verwaltung bei der Festlegung der zweckgeeigneten Mittel gelassen ist. Das ist aber nicht die Bandbreite bei der Utberprüfung im Bereich der unbestimmten Begriffe, nicht die Bandbreite nach der Vertretbarkeitslehre, sondern eine Bandbreite der Möglichkeiten, den $Z$ weck aus der Sicht der Verwaltungsbehörden zu verfolgen. Hier - darum habe ich eben auf die Unterscheidung zwischen Polizeirecht und Sicherheitsrecht besonders hingewiesen - müßte man ganz deutlich unterscheiden zwischen der Auffüllung des Ermessens im Polizeirecht durch die dort niedergelegten Grundsätze der Geeignetheit und des Ubermaßverbots und der Funktion im Atomrecht, im Immissionsschutzrecht, im Wasserrecht, wo wir diese Zwecknormen haben. Sie bestimmen die Frage des Einsatzes der Mittel. Hier hat in der Tat die Verwaltung festzustellen, was zweckmäßig ist. Die Gerichtsbarkeit hat nur zum einen die materielle Normsubsumtion und zum anderen die Einhaltung des Verfahrens zu überprüfen; die Gerichtsbarkeit hat aber nicht selbst die Entscheidung zu treffen. Das sind zwei wesentliche Unterschiede.

Herr von Mutius - Herr Götz hat dem nachgestoßen -, Sie haben unter anderem auf These 12 hingewiesen und gesagt, ich führte dort gleichrangig Individual- und Kollektivschutzgüter auf, ohne zu beachten, daß hier „öffentliche Sicherheit und öffentliche Ordnung" stehe, und ich legte auf diese Veröffentlichung kein Gewicht. Sie haben dann die Frage, wie es laufe, wenn man es in den privaten Bereich bringe, etwa unter dem Schlagwort „Eltern haften für ihre Kinder“, hineingenommen. Dazu ganz deutlich: Der Begriff der öffentlichen Sicherheit ist unter allgemeinem Anklang zum Beispiel durch die Begriffe 
Gesundheit, Leben, Freiheit ausgefüllt worden. Diesen Auffüllungsbegriffen folge ich und messe dem Begriff der Öffentlichkeit hier keine separate Bedeutung zu.

Wenn Sie dann glauben, mich bei den Bauwichnormen bei einem Widerspruch ertappt zu haben, muß ich das zurückweisen, denn Sie haben die Bedeutung der Bauwichnormen für den Planungs- und den Feuerschutzbereich herausgestellt. Die Bauwichnormen haben zunächst einmal die Bedeutung des Gefahrenschutzes, soweit ich daraus Ansprüche für den Nachbarn, für das Individuum, ableite. Die Feuerschutzbestimmungen haben eine eigene Bedeutung. Sie liegen neben den Bauwichnormen. Dafür haben wir eigene Normen, die dann in der Tat dem Allgemeinschutz dienen und zusätzlich vielleicht dem Individualschutz.

Ich hätte hierzu natürlich noch einiges anzumerken, vor allem zur gewachsenen Bedeutung der Zwecknormen, trotz ihrer erheblichen Unbestimmtheit - Herr Breuer, das gebe ich Ihnen absolut zu -; aber ich habe im Referat ausgeführt, daß der Rückgriff auf die Zwecknormen wohl die einzige Möglichkeit für den Gesetzgeber ist, dieser Materie überhaupt habhaft werden zu können. Die Zwecknormen bestimmen dementsprechend die einzelnen Handlungspflichten.

Vorsitzender: Zum dritten Problemkreis „Adressaten und Mittel des polizei- und ordnungsbehördlichen Handelns" wird Herr Ossenbühl die Diskussion eröffnen.

Ossenbühl: Herr Vorsitzender, Sie haben den Problemkreis der polizeilichen Verantwortung an die letzte Stelle gesetzt. Nach der gestellten Thematik ist er dort auch sicher richtig plaziert. Gleichwohl bin ich der Meinung, daß ihm in den Referaten vielleicht doch etwas zuwenig Aufmerksamkeit gewidmet worden und daß dieser Problembereich noch ergänzungsbedürftig ist. Ich will versuchen, mit einigen Stichworten und wenigen Sätzen die Problempalette zu erweitern.

Herr Erichsen hat mit Recht bemerkt, daß die Welt auch im Polizeirecht komplexer geworden sei. - Damenringkämpfe, das Tragen von Dekolletés, die unsere Großväter polizeirechtlich stimuliert haben, sind für uns natürlich kein polizeirechtliches Problem mehr. Das Konfliktmaterial, das wir heute vorfinden, ist von anderer Art. Es ist in der Tat komplexer.

Ich will nur einige Stichworte nennen. Es sind beispielsweise die Ölunfälle, die hier nur ganz kurz angesprochen worden sind. Es ist allgemein die Bekämpfung von Zivilisationsgefah- 
ren. Es ist die Verkehrsblockade, die zu erheblichen Schäden führen kann, wie wir in dem Hannoveraner Fall gesehen haben. Es ist das Beschmieren von Hauswänden mit polizeiwidrigen Parolen, und es ist - nicht zu vergessen - der Fall des Schweinemästers, der ja im doppelten Sinne des Wortes immer noch zum Himmel stinkt.

Um diese Fälle, die uns heute bewegen, vom Haftungstatbestand her zu erfassen, müssen wir die überkommenen Haftungstatbestände neu überdenken. Das gilt für den Verursachungstatbestand, dem die polizeirechtliche Aufmerksamkeit bisher in erster Linie gegolten hat. Das gilt aber auch für die Zustandshaftung, soweit sie an das Eigentum anknüpft. Die schlichte These von Herrn Erichsen, daß der verfassungsrechtliche Eigentumsschutz schon bei der Feststellung der Störerfrage zum Tragen komme, scheint mir zumindest zweifelhaft. Es ist nämlich die Frage, ob man den Eigentumsbegriff des Polizeirechts überhaupt mit dem verfassungsrechtlichen Eigentumsbegriff egalisieren darf. Wir haben doch den Fall, daß ein und derselbe Begriff in verschiedenen gesetzlichen und rechtlichen Zusammenhängen einen durchaus unterschiedlichen Sinngehalt hat, sehr häufig.

Nach meiner Meinung muß man überlegen, ob nicht für das Polizeirecht ein spezifisch polizeirechtlicher Eigentumsbegriff entwickelt werden muß, in dem danach gefragt wird, warum denn das Polizeirecht für die polizeirechtliche Verantwortlichkeit an das Eigentum anknüpft. Ist es das Vorteil-NachteilPrinzip? Oder ist es etwa der Gedanke, daß der Eigentümer die umfassendste Herrschaftsgewalt hat? Oder ist es ein drittes Kriterium? Je nachdem, welcher Anknüpfungspunkt gewählt wird, fallen die Ergebnisse im Einzelfall höchst unterschiedlich aus.

Ich meine überhaupt, daß man das überkommene unangefochtene Prinzip der rigorosen Gefährdungshaftung, das ja für das Polizeirecht gilt, vielleicht in Frage stellen sollte, und zwar unter zwei Gesichtspunkten: einmal unter dem Gesichtspunkt einer Neuabgrenzung der Risikosphären, was auch schon bei Herrn Erichsen anklingt. Bei dieser Neuabgrenzung müssen wir im Auge behalten, daß es letztlich um etwas geht, was hier schon angeklungen ist, nämlich um die Finanzierung der Gefahrenabwehr. Das steckt ja immer in gravierendem Maße hinter der Störerfrage. Ich meine, diese Risikoabgrenzung sei notwendig. Nur ist sie mir mit den Richtpunkten, die Herr Erichsen angegeben hat, "Stabilisierung des Gesamtsystems" auf der einen Seite und "durch die Rechtsordnung zugewiesener Bereich des einzelnen" auf der anderen Seite, zu vage markiert. 
Zweitens sollte man vielleicht überlegen, ob nicht noch eine weitere heilige Kuh des Polizeirechts zu schlachten ist, ob man nämlich in die polizeirechtlichen Haftungstatbestände nicht möglicherweise in größerem Umfang, als das schon bisher zum Teil geschehen ist, subjektive Elemente einbaut. Ich gebe dies nur zur Erwägung, ohne selbst schon eine feste Position in dieser Frage zu haben. Unter diesen beiden Aspekten, meine ich, müßte man die gesamten Haftungstatbestände des Polizeirechts neu überdenken. Die Verursachungshaftung habe ich in den vorgenannten Bemerkungen mit Absicht herausgelassen.

Berg: Es ist zwar schon bedauernd darauf hingewiesen worden, daß das Polizeirecht im Unterricht des öfentlichen Rechts noch immer eine wichtige Rolle spielt; weil es aber so ist, möchte ich einmal eine Frage zum Polizeirecht im Universitätsunterricht stellen. Im Hinblick auf das polizeiliche Mittel sehe ich Schwierigkeiten in der Systematik, und zwar unterschiedlicher Art bei den beiden Referenten: Herr Erichsen hat die Frage des Mittels - ohne daß dies in den Thesen deutlich geworden wäre - im Rahmen der Verantwortlichkeit unter dem Aspekt der „Konkretisierung“ angesiedelt. Herr Knemeyer hat andererseits mit der Eliminierung des Ermessens die Mittelproblematik offenbar erheblich aufgewertet. Mir scheint, daß die Prüfung der Rechtmäßigkeit einer Polizeiverfügung dadurch nicht leichter, vielleicht umständlicher und im Aufbau unübersichtlicher geworden ist.

Konkrete Frage an die Referenten: Herr Erichsen, soll tatsächlich eine einheitliche Prüfung von Verantwortlichkeit und Mittel vorgenommen werden? Herr Knemeyer, ist es nach Ihrer Systematik - unabhängig davon, ob ein verantwortlicher Störer vorhanden oder mit Recht betroffen ist - stets geboten, Geeignetheit, Erforderlichkeit und Verhältnismäßigkeit des Mittels zu untersuchen?

Selmer: Einige Bemerkungen zu den Leitsätzen 21 ff. des Referats von Herrn Erichsen, und zwar die Begrenzung der Äquivalenztheorie durch begrenzende Topoi betreffend: Mit großem Vergnügen habe ich zunächst feststellen können, Herr Erichsen, daß Sie es vermieden haben, uns hier einen scheinbar subsumtionsfähigen neuen Topos vorzugaukeln, wie wir das aus - wie man sagen muß — dem größten Teil der Lehrbücher kennen; ich nenne nur die Formeln von der polizeiwidrigen oder rechtswidrigen Erfolgsverursachung, die Formel vom sozialadäquaten Verhalten und die Theorie von der unmittelbaren Verursachung. Sie haben dies dankenswerterweise ver- 
mieden. Sie haben jedenfalls zunächst vermieden, diesen Formeln eine neue Leerformel hinzuzufügen, und haben sich wie ich meine, völlig zu Recht - auf den Satz zurückgezogen, daß es hier um die Verteilung des Risikos zwischen betroffener Allgemeinheit und dem einzelnen gehe.

Hier allerdings, meine ich, beginnen die Probleme erst. Ich glaube, Herr Ossenbühl hat das eben bereits angedeutet. Dem haben Sie sich, wenn ich es recht sehe, vielleicht doch etwas entzogen und sich dann in Leitsatz 24 wieder auf eine scheinbar überzeugende, aber letztlich ebenfalls leerformelhafte Lösung zurückgezogen, indem Sie sagten, der einzelne dürfe nur dann als verantwortlich in Anspruch genommen werden, wenn er den ihm durch die Rechtsordnung zugewiesenen Bereich überschreite. Damit aber bin ich eigentlich genauso schlau wie zuvor. Hier ist die Frage der Abgrenzung der Risikosphären vielleicht doch etwas vorschnell, etwas eilig übergangen worden. Ich frage mich: Betrifft diese Frage nicht überhaupt eines der Hauptprobleme? Und: Ist hier nicht die Polizei gelegentlich überfordert? Ist nicht die Polizei überfordert, wenn sie entscheiden soll, ob etwa dem (bisher rechtmäßig) lärmenden Fischgroßhändler (vgl. BVerwGE 38, 209) der Betrieb entschädigungslos geschlossen werden soll oder nicht? Geht es hier nicht eigentlich um einen Bereich, der seiner Eigenart nach letztlich doch in die Zuständigkeit des Gesetzgebers fällt? Dies nur als Frage.

Schließlich ein letzter Punkt - Herr Ossenbühl hat auch diesen bereits berührt -: die Verlagerung der Eigentumsproblematik in die Störerproblematik. Auch ich habe hier gewisse Bedenken, die Frage, ob das Eigentum des Adressaten in einem konkreten Fall enteignungsrechtlich geschützt ist oder nicht, bereits in den Störerbegriff hineinzuverlagern. Der Schutz der Allgemeinheit könnte hier zu kurz kommen, weil Sie in manchem Falle diesen Schutz nur noch über ein formales Enteignungsverfahren bewerkstelligen könnten, sofern keine Notstandsvoraussetzungen vorliegen. Ich meine deshalb, daß wir ruhig den Satz aufstellen sollten, daß in bestimmten Fällen auch das Eigentum des Störers schützenswert sein kann mit der Folge, daß - wofür wir freilich eine Vorschrift wie etwa die des $\$ 51$ der Gewerbeordnung brauchen — durch die Polizei selbst, also durch die zuständige Ordnungsbehörde, der Betrieb untersagt und zugleich Entschädigung geleistet werden könnte.

Bachof: Ich kann mich kurz fassen, weil ich weitgehend mit dem Vorredner und mit Herrn Ossenbühl übereinstimme. Der Schweinemästerfall stinkt noch mehr zum Himmel, wenn wir 
ihn variieren und die Mästerei durch einen ganz gewöhnlichen Bauernhof ersetzen. In tatsächlicher Hinsicht stinkt es dann wohl weniger, aber rechtlich stinkt der Fall dann noch mehr. Die Rechtsprechung zieht auch beim Bauernhof dieselben Konsequenzen: der Bauernhof, wenn geruchsbelästigend, muß einer neuen städtischen Siedlung weichen. Das halte ich für richtig; aber daß er entschädigungslos soll weichen müssen, das halte ich für eine unmögliche Folge.

Um mit den Schwierigkeiten fertig zu werden, müssen wir m. E. am herkömmlichen Begriff des Störers ansetzen. Die bisherigen Theorien arbeiten weitgehend mit unbrauchbaren Leerformeln. Sie werden aber nicht dadurch konkreter, daß man den dem Verantwortlichen zugewiesenen Bereich, von dem Herr Erichsen in These 25 spricht, dahin definiert, er sei ,eine im Einzelfall je nach Rechtsgüterkonstellation variable Größe". Ich jedenfalls weiß damit nicht mehr als vorher.

Ich meine, beim Zusammentreffen zweier erst durch dieses Zusammentreffen zur Unverträglichkeit führender Verhaltensweisen oder Zustände - das ist ja das schwierigste Problem, dahin gehören der Schweinemästerfall und fast alle anderen Fälle, die uns Kopfschmerzen bereiten - wird man darauf abstellen müssen, wo denn eigentlich die Verantwortung für die Veränderung liegt; die Verantwortung dafür, daß das, was bisher gemeinverträglich war, nun nicht mehr gemeinverträglich ist. Diese Verantwortung trifft, wenn eine neue Siedlung gebaut wird und ein vorhandener Bauernhof nun wegen der Fliegenplage usw. nicht mehr gemeinverträglich ist, eindeutig die neue Siedlung. Es ist allerdings falsch, wenn einige Verwaltungsgerichte jetzt gemeint haben, das Problem so lösen $\mathrm{zu}$ können, daß sie dem Bauern einen Anspruch auf Unterbleiben der Errichtung der Siedlung einräumen, weil eine den vorhandenen Hof nicht berücksichtigende Planung rechtswidrig sei. Nein, einer notwendigen städtebaulichen Entwicklung kann ein bestehender Betrieb - sei es ein Gewerbebetrieb, ein Bauernhof oder was auch immer - nicht mit Erfolg entgegengehalten werden. Aber eine ganz andere Frage ist es, ob der Betrieb entschädigungslos weichen muß. Das muß er m. E. nicht. Da die Verantwortung für die Zustandsveränderung bei der neuen Planung liegt, muß der Planunternehmer die Entschädigung tragen.

Fazit: Entweder müssen wir den Störerbegriff einschränken, indem wir den für eine Veränderung nicht Verantwortlichen aus dem Störerbegriff herausnehmen; oder aber wir müssen von dem Dogma Abschied nehmen, daß der Störer niemals entschädigungsberechtigt sein könne. 
Friauf: Ich kann mich weitgehend dem anschließen, was die Herren Bachof und Ossenbühl bereits gesagt haben. - Herr Erichsen hat uns heute morgen um eine interessante Dreistufentheorie der polizeilichen Güterabwägung bereichert; Güterabwägung bei der Gefahrenqualifikation, Güterabwägung bei der Störerbestimmung und Güterabwägung bei der Wahl des anzuwendenden Mittels. Ich möchte diese Theorie auf ihrer zweiten Stufe - nur dazu nehme ich hier Stellung - nachdrücklich unterstützen. Es handelt sich insoweit um den unbedingt notwendigen Versuch, die bisherige absolute Starrheit des Störerbegriffs aufzulösen. Sie wurde uns aus einer Zeit tradiert, in der die Störerverantwortung tatsächlich im allgemeinen auf den eigenen beherrschbaren Bereich des einzelnen begrenzt blieb. Diese Voraussetzung hat sich indessen seit Jahrzehnten geändert. Wir haben es vielfach mit Gefahrensituationen zu tun, an die bei der Herausbildung des klassischen Störerbegriffs niemand denken konnte.

Heute werden durch die Störerqualifikation oftmals Risiken in einer Weise verteilt, für die materiell keine Berechtigung erkennbar ist. Bei der Handlungshaftung hat man die Probleme noch einigermaßen in den Griff bekommen können, weil die herrschende Theorie der unmittelbaren Verursachung verhältnismäßig flexibel ist und deshalb meist sach- und interessengerechte Lösungen ermöglicht. Bei der Zustandshaftung ist das dagegen bisher nicht hinreichend gelungen. So "stinken" nicht nur die Fälle des Fischgroßhändlers und des Schweinemästers nach wie vor „zum Himmel" — um die früher erwähnten Beispiele aufzugreifen - sondern auch die Störerhaftung für Planungsschäden, die Kriegsschadensfälle, die Ölschadensfälle usw.

Ich glaube nicht, daß man mit Herrn Ossenbühl die Lösung der Probleme der Zustandshaftung des Eigentümers darin suchen kann, daß man einen eigenständigen polizeilichen Eigentumsbegriff entwickelt. Dieser Weg ist schon deshalb nicht gangbar, weil wir es bei den betreffenden Vorschriften der Polizeigesetze mit einer klaren Verweisung auf den Eigentumsbegriff des BGB zu tun haben. Der Eigentümer, der in Anspruch genommen werden soll, ist der privatrechtliche Eigentümer der störenden Sache. Die Zustandshaftung läßt sich deshalb nicht dadurch begrenzen, daß man ihn dort, wo eine Haftung ungerechtfertigt erscheint, im polizeirechtlichen Sinne als Nicht-Eigentümer qualifiziert.

Wir müssen deshalb nach anderen Lösungswegen suchen. Einen ersten Schritt kann die Rechtsanwendung auch ohne Eingreifen des Gesetzgebers tun. Er bestünde in einer verfassungskonformen Reduktion der Störerhaftung, der sie auf den Um- 
fang der Sozialpflichtigkeit des Eigentümers zu beschränken hätte. Längerfristig ist allerdings der Gesetzgeber selbst zur Neuregelung dieses Bereichs aufgerufen. Dabei muß unter anderem überlegt werden, ob nicht für bestimmte Tatbestände das Dogma von der unbedingten Entschädigungslosigkeit des Störers aufzugeben ist. In den Fällen, in denen die Zustandshaftung letztlich Störungen korrigiert, die nicht mehr in die Verantwortungssphäre des einzelnen Eigentümers fallen, müssen wir ihn entschädigen, auch wenn formal die Voraussetzungen des derzeitigen weitgespannten Störerbegriffs erfüllt sind. Ich lasse bewußt offen, ob - sofern der Gesetzgeber untätig bleiben sollte - die Rechtsprechung schon nach geltendem Recht diesen weiteren Schritt gehen kann oder ob es dazu unter allen Umständen einer Gesetzesänderung bedürfte.

Vogel: Ein letzter Satz zum Ermessen: gerade weil der Richter nachträglich immer klüger ist als der handelnde Polizeibeamte, muß, meine ich, der Beamte Ermessen haben.

Jetzt noch kurz zu zwei Einzelfragen: Herr Erichsen, ich gebe Ihnen zu, daß das Problem der polizeilichen Kausalität bislang nicht befriedigend gelöst worden ist. Ich räume Ihnen auch ein, daß Ihre Theorie den Fall des Olunfalls sachgerecht lösen würde. Wie aber entscheiden Sie den Fall des Baumes auf meinem Grundstück, der, ohne daß mir eine Sorgfaltsverletzung zur Last fällt, durch Blitzschlag getroffen ist und sich nun nach außen neigt und den Verkehr oder sonstwen gefährdet?

Abschließend noch zu der Frage des Selbstmords, wie sie Herr Knemeyer heute früh angesprochen hat. Ich will mich gewiß nicht mit jenen Literaten identifizieren, die, nachdem ihnen inzwischen Rauschgift und ähnliches keinen Reiz mehr bieten, neuerdings das Recht auf den eigenen Tod proklamieren: wohlgemerkt, nicht als das Recht des unheilbar Kranken, endlich von der Maschine abgeschaltet zu werden, sondern im Sinne eines exzessiven ethischen Solipsismus (wie etwa auch bei der Formel "mein Bauch gehört mir") oder sogar eines Rechts auf den "lustvollen Suizid". Ich will mich also mit solchen Thesen gewiß nicht identifizieren; aber wenn Sie, Herr Knemeyer, heute früh gemeint haben, der Selbstmörder handele grundsätzlich unfrei, oder die Behörde müsse hiervon doch jedenfalls ausgehen - Sie haben es besser gesagt, ich kann es nicht ganz genau wiederholen - , dann scheint mir dies doch der oft sehr schwierigen menschlichen Problematik, die hinter solchen Ereignissen steht, nicht voll gerecht zu werden, ebenso wie unsere herkömmliche polizeirechtliche Dogmatik diesen Fragen nicht voll gerecht geworden ist. 
Knemeyer: Herr Vogel, ich möchte darauf gleich antworten. Mir ist in der Tat nicht ganz klargeworden, wo Sie die Problematik der Lösung, die ich hier nur skizziert habe, sehen wollen. Darf ich danach fragen.

Vogel: Ich glaube nicht, daß man in dieser Allgemeinheit sagen kann, ein Mensch handele in solch einer Grenzsituation unfrei; das würde das Problem verkürzen. Nach meiner Meinung ist das Problem sehr viel schwieriger. Das ist kein Vorwurf gegen Sie, sondern nur ein Appell an uns alle - ich schließe mich da durchaus ein -, über diese Fragen noch ernsthafter und subtiler nachzudenken, als wir es bisher schon getan haben.

Knemeyer (Schlußwort): Herr Vogel, dann stimme ich Thnen völlig zu.

Herr Berg, Sie haben kurz - da brauche ich nur noch einen Punkt direkt anzusprechen - darauf hingewiesen, daß ich die Mittelproblematik aufgewertet hätte. Das ist in der Tat richtig. Sie haben dann die Frage nach dem Störer angeschlossen. Dieser Frage nach dem Störer brauchte ich in dem Bereich, den ich zu bearbeiten hatte, nämlich der Spezialermächtigungen, nicht näher nachzugehen, weil sich dort die Frage nach dem Störer eigentlich erledigt. Der Störer ist in der Einzelnorm angesprochen. Soweit es auf die Generalklausel hinzielt, muß ich den Störer selbstverständlich in die Mittelbestimmung mit hineinnehmen und darf beides nicht voneinander trennen.

Damit brauche ich bereits keine Einzelerwiderungen mehr zu geben. Wenn ich den einen oder anderen übergangen haben sollte, meine Herren, verzeihen Sie mir das bitte.

Lassen Sie mich zum Schluß nur noch etwas Allgemeines sagen. Bei der Utberprüfung der Fülle von verschiedenartigsten Handlungsvollmachten im Rahmen der Vorarbeiten zum Referat stellte sich sehr bald heraus, daß die induktive Methode zu abweichenden Ergebnissen von der von der herrschenden Meinung prinzipiell vertretenen Auffassung über Aufgabenzuweisung, Befugnis und Ermessen führen würde. In der Bedeutung der Aufgabenzuweisungsnormen habe ich keinen wesentlichen Widerspruch erfahren; auch in meiner Einordnung der Befugnisnormen nicht, vielleicht deswegen nicht, weil wir nicht so weit gekommen sind. Um so stärkeres Feuer habe ich dann zur Frage des Ermessens bekommen. Ich habe in der Tat das Ermessen - auch da darf ich noch einmal unseren Vorsitzenden von heute morgen zitieren - aus den wenigen ver- 
bliebenen Schlupflöchern herausgeholt und versucht, dieses Ermessen aufzufüllen.

Wir müssen doch eines sehen: Wir arbeiten zwar im akademischen Unterricht immer mit Ermessen, und wir arbeiten auch zwischenzeitlich manchmal dann noch mit Ermessen, wenn wir glauben, sonst keine Entscheidung mehr zu finden. Schauen wir uns aber einmal die Rechtsprechung im einzelnen an, so stellen wir sehr schnell fest, daß die Gerichte in der großen Vielzahl der Entscheidungen für den Begriff Ermessen ganz handfeste Formeln gefunden haben, Formeln allerdings, die hier und da voneinander abweichen. Aber es ist eben nicht mehr ein irgendwie schwammiges Ermessen, sondern bereits ein aufgefülltes Ermessen. Ich habe nicht viel anderes getan, als das Auswahlermessen aufzufüllen, allerdings nicht mit Formeln ad hoc in Salamimethode, sondern ich habe versucht, anhand des Polizeirechts aufzuzeigen, wo mir der Ansatz für die Auffüllung des Ermessens zu liegen scheint, nämlich in den drei mittelbestimmenden und dirigierenden Grundsätzen der Geeignetheit, der Erforderlichkeit und der Verhältnismäßigkeit.

Ich möchte diesen schmalen Ansatz zu einem System nicht noch einmal zu erläutern versuchen. Die Diskussion hat wesentliche Details hinzugefügt, neuralgische Punkte aufgezeigt, vor allem das Ermessen, und auch Korrekturen angebracht. In den Ergebnissen liegen wir - das glaube ich nach Utberprüfung einer Reihe von Fällen vor dieser Tagung, in denen ich versucht habe, das System anzuwenden, sagen zu können gar nicht weit auseinander. Es ist einfach nur das Bemühen gewesen, diesen Begriff des Ermessens handzuhaben und ihn nicht mehr als ein zu schwammiges Etwas zu sehen.

Meine Herren, ich darf mich für die Diskussion ganz herzlich bedanken.

Erichsen (Schlußwort): Ich möchte zunächst auf die zu Punkt3 unserer Diskussionsgliederung erhobenen Fragen eingehen und darf dazu einleitend zwei Sätze aus meinem Referat, die ich der Kürze wegen habe streichen müssen, noch nachtragen.

Ich habe dort gesagt: „Der Eigentümer, von dessen Grundstück das aus dem Tanklastzug auslaufende Öl in den Einzugsbereich eines Wasserwerks einzusickern droht, leitet - folgt man dem Bundesverwaltungsgericht - keine Stoffe ein. Er ist daher auch kein Störer. Das gleiche gilt für die im Außenbereich bauplanungsrechtlich zulässig betriebene Schweinemästerei". 
Ich stimme also weitgehend mit dem überein, was hier insbesondere von Herrn Bachof gesagt worden ist.

Ich habe versucht, das Problem über eine güterabwägende, das Eigentum einbeziehende Definition des Störerbegriffs zu lösen. Das hat zur Folge, daß ein Eingriff in das im Rahmen der risikozurechnenden Güterabwägung nicht konsumierte Schutzgut eine Entschädigung auslöst.

Darin lag für mich ein wesentlicher Ansatzpunkt. Ich möchte gerne hinzufügen, daß die Regelungen über die Entschädigung bei Inanspruchnahme des Nichtstörers in Zukunft erheblich fruchtbarer gemacht werden könnten, um jene Kollisionsfälle, die bisher so unlösbar scheinen oder - wie hier gesagt worden ist - „zum Himmel stinken“, einer befriedigenden Lösung zuzuführen.

Was Thr Beispiel mit dem Baum betrifft, Herr Vogel, so meine ich, daß Sie wohl mit einer Inanspruchnahme rechnen müssen.

Ich würde es indes nicht für glücklich halten - insoweit stimme ich völlig mit Herrn Friauf überein -, einen eigenen Eigentumsbegriff für den Bereich des Polizeirechts zu entwikkeln. Ich glaube in der Tat, daß mit den von mir angebotenen, sicherlich in ihrer Abstraktheit recht vagen Formeln die Probleme lösbar sind.

Herr Berg, Sie haben darauf hingewiesen, daß das Mittel von mir nur im Hinblick auf die Konkretisierung des im Verhältnis zum Polizeigut gegenläufigen Rechtsguts angesprochen worden ist. Das ist in der Tat richtig; es handelt sich hier um einen weiteren Punkt meiner Verlustliste.

Ich möchte mich allerdings - in Utbereinstimmung mit den Andeutungen von Herrn Götz - dagegen zur Wehr setzen, hier von einer ganz sauberen Trennung auszugehen. Mir ging es in meinem Referat auch darum, das Prozeßhafte einer solchen Entscheidung deutlich zu machen. Deshalb habe ich - ich darf anknüpfen an das, was Herr Friauf gesagt hat - Güterabwägung auf mehreren Stufen vorzuführen versucht. Diese mehreren Stufen sind Stufen eines Entscheidungsprozesses, um den es mir geht.

Schließlich möchte ich doch noch einmal auf die Frage des staatswissenschaftlichen Gesamtzugriffs der Sondergesetze zurückkommen. Das Verwaltungsverfahrensgesetz des Bundes wird am 1. Januar 1977 in Kraft treten. Angesichts der von mir angesprochenen und in den Anwendungsbereichsregelungen des Gesetzes respektierten Entwicklung zur sondergesetz- 
lichen, mit der Entstehung von organisatorischen und rechtlichen Eigenbereichsstrukturen verbundenen Regelung weiß ich nicht, ob das nicht eine Art Abschiedschoral für die von Otto Mayer geprägte Dogmatik des allgemeinen Verwaltungsrechts sein wird. Wir sollten alles tun, um dem entgegenzuwirken, und wir werden im Hinblick auf das jetzt als Auffangbecken verfügbare Verwaltungsverfahrensgesetz das zu tun haben, was ich im Hinblick auf das Polizei- und Ordnungsrecht versucht habe. Es wird darum gehen, dieses Gesetz als Denk. und Argumentationsmodell für die Rückbindung der Sonderverwaltung und der Sonderorganisation verfügbar zu halten.

Zum Abschluß darf ich mich bei Thnen allen sehr herzlich für die vielen Anregungen bedanken, die ich in der Diskussion erhalten habe. Ich bitte um Nachsicht dafür, daß ich aus Zeitgründen nicht auf alles habe eingehen können. Schließlich möchte ich nicht versäumen, Herrn Knemeyer auch an dieser Stelle meinen herzlichen Dank für eine sehr partnerschaftliche Zusammenarbeit zu sagen.

Vorsitzender: Meine sehr verehrten Herren Kollegen! Auch mir bleibt nur übrig zu danken, und zwar allen Rednern dieser Diskussion. Die Referenten konnten kein höheres Lob erzielen als die Lebendigkeit und den Ideenreichtum unserer nachmittäglichen Auseinandersetzung. Ich danke allen. 
